\title{
Required Number of Records for ASCE/SEI 7 Ground- Motion Scaling Procedure
}

By Juan C. Reyes and Erol Kalkan

Open-File Report 2011-1083

U.S. Department of the Interior

U.S. Geological Survey 
This page intentionally left blank 


\section{Required Number of Records for ASCE/SEI 7 Ground- Motion Scaling Procedure}

By Juan C. Reyes and Erol Kalkan

Open-File Report 2011-1083

U.S. Department of the Interior

U.S. Geological Survey 


\title{
U.S. Department of the Interior \\ KEN SALAZAR, Secretary
}

\author{
U.S. Geological Survey \\ Marcia K. McNutt, Director \\ U.S. Geological Survey, Reston, Virginia 2011
}

For product and ordering information:

World Wide Web: http://www.usgs.gov/pubprod/

Telephone: 1-888-ASK-USGS

For more information on the USGS-the Federal source for science about the Earth,

its natural and living resources, natural hazards, and the environment:

World Wide Web: http://www.usgs.gov/

Telephone: 1-888-ASK-USGS

Suggested citation: Reyes, J.C. and Kalkan, E., 2011, Required number of records for ASCE/SEI 7 ground-motion scaling procedure: U.S. Geological Survey Open-File Report 2011-1083, 29 p. [http://pubs.usgs.gov/of/2011/1083/].

Any use of trade, product, or firm names is for descriptive purposes only and does not imply endorsement by the U.S. Government.

Although this report is in the public domain, permission must be secured from the individual copyright owners to reproduce any copyrighted material contained within this report. 


\section{Contents}

Page

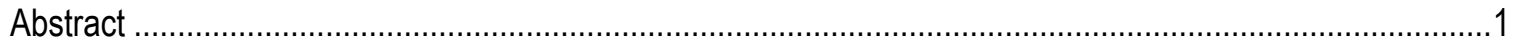

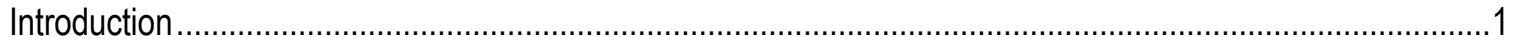

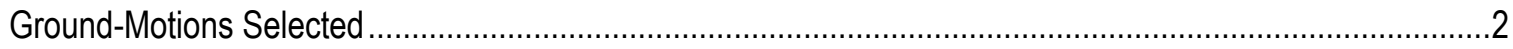

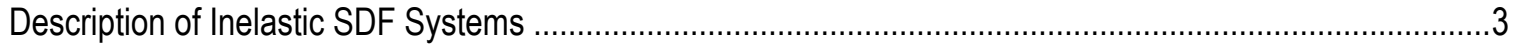

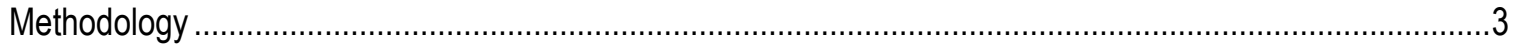

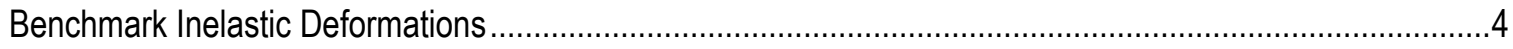

Evaluation of ASCE/SEI 7 Scaling Procedure: Less Than Seven Ground-Motions .....................................

Evaluation of ASCE/SEI 7 Scaling Procedure: Seven or More Ground-Motions..........................................

Modal-Pushover-Based Scaling Procedure: Alternative to the ASCE/SEI 7 Scaling Method ..........................7

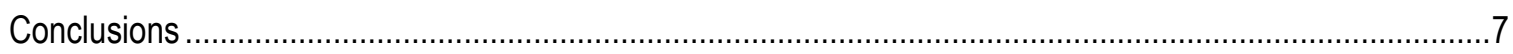

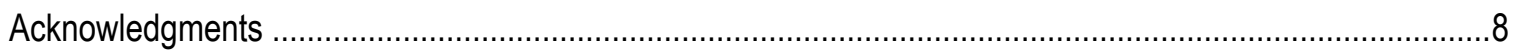

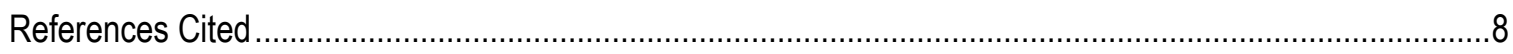

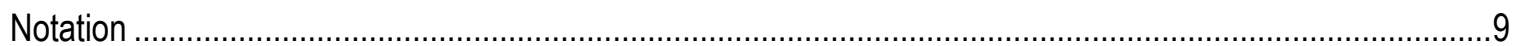




\title{
Required Number of Records for ASCE/SEI 7 Ground- Motion Scaling Procedure
}

\author{
By Juan C. Reyes ${ }^{1}$ and Erol Kalkan ${ }^{2}$ \\ 1 Universidad de los Andes, Bogota, Colombia, jureyes@uniandes.edu.co. \\ 2 U.S. Geological Survey, Menlo Park, CA 94025, ekalkan@usgs.gov.
}

\begin{abstract}
The procedures and criteria in 2006 IBC (International Council of Building Officials, 2006) and 2007 CBC (International Council of Building Officials, 2007) for the selection and scaling ground-motions for use in nonlinear response history analysis (RHA) of structures are based on ASCE/SEI 7 provisions (ASCE, 2005, 2010). According to ASCE/SEI 7, earthquake records should be selected from events of magnitudes, fault distance, and source mechanisms that comply with the maximum considered earthquake, and then scaled so that the average value of the 5-percent-damped response spectra for the set of scaled records is not less than the design response spectrum over the period range from $0.2 T_{n}$ to $1.5 T_{n} \sec$ (where $T_{n}$ is the fundamental vibration period of the structure). If at least seven ground-motions are analyzed, the design values of engineering demand parameters (EDPs) are taken as the average of the EDPs determined from the analyses. If fewer than seven ground-motions are analyzed, the design values of EDPs are taken as the maximum values of the EDPs. ASCE/SEI 7 requires a minimum of three ground-motions. These limits on the number of records in the ASCE/SEI 7 procedure are based on engineering experience, rather than on a comprehensive evaluation. This study statistically examines the required number of records for the ASCE/SEI 7 procedure, such that the scaled records provide accurate, efficient, and consistent estimates of "true" structural responses. Based on elastic-perfectly-plastic and bilinear single-degree-of-freedom systems, the ASCE/SEI 7 scaling procedure is applied to 480 sets of ground-motions. The number of records in these sets varies from three to ten. The records in each set were selected either (i) randomly, (ii) considering their spectral shapes, or (iii) considering their spectral shapes and design spectral-acceleration value, $A\left(T_{n}\right)$. As compared to benchmark (that is, "true") responses from unscaled records using a larger catalog of ground-motions, it is demonstrated that the ASCE/SEI 7 scaling procedure is overly conservative if fewer than seven ground-motions are employed. Utilizing seven or more randomly selected records provides a more accurate estimate of the EDPs accompanied by reduced record-to-record variability of the responses. Consistency in accuracy and efficiency is achieved only if records are selected on the basis of their spectral shape and $A\left(T_{n}\right)$.
\end{abstract}

\section{Introduction}

When nonlinear response history analysis (RHA) is required for design verification of building structures, the International Building Code (2006) and California Building Code (2007) refer to the ASCE/SEI 7 Section 16-21 (ASCE, 2005, 2010).

${ }^{1}$ Ground motion selection and scaling procedure for two-dimensional analysis of structures are same in both ASCE/SEI 7-05 and 7-10
According to these documents, earthquake records should be selected from events of magnitudes, fault distance, and source mechanisms that comply with the maximum considered earthquake.

For two-dimensional analysis of symmetricplan buildings, ASCE/SEI 7 requires intensitybased scaling of ground-motion records using

documents; therefore in the remaining of this report, we simply refer to this method as the ASCE/SEI 7 scaling procedure. 
appropriate scale factors, so that the average (that is, mean ${ }^{2}$ ) value of the 5-percent-damped response spectra for the set of scaled records is not less than the design response spectrum over the period range from $0.2 T_{n}$ to $1.5 T_{n}$ (where $T_{n}$ is the elastic first-"mode" vibration period of the structure). For three-dimensional analyses, ground-motions should consist of pairs of appropriate horizontal ground-motion acceleration components. For each pair of horizontal ground-motion components, a square root of the sum of the squares (SRSS) spectrum should be constructed by taking the SRSS of the 5-percent-damped response spectra of the unscaled components. Each pair of motions are then scaled with the same scale factor such that the mean of the SRSS spectra from all horizontal component pairs does not fall below the corresponding ordinate of the target spectrum in the period range from $0.2 T_{n}$ to $1.5 T_{n}$. The design value of an engineering demand parameter (EDP)-member forces, member deformations or story drifts-is taken as the mean value of the EDP over seven or more ground-motions, or as its maximum value over all ground-motions, if the system is analyzed for fewer than seven groundmotions. This procedure requires a minimum of three records. The limits on the number of groundmotions in ASCE/SEI 7 were based on engineering experience rather than on a comprehensive evaluation (Charlie Kircher, oral commun.).

This study, for the first time, statistically examines the required number of records for the ASCE/SEI 7 procedure such that the scaled records provide accurate, efficient, and consistent estimates of "true" median structural responses. The adjective "accurate" refers to the discrepancy between the "true" responses and those computed from the scaling procedure. The adjective "efficient" refers to the record-to-record (that is, intra-set) variability of responses, and the adjective "consistent" refers to the ground-motion set-to-set (that is, inter-set) variability of accuracy and efficiency. Smaller values of inter- and intra-set

2In the remaining, "mean" is used in lieu of "arithmetic mean". dispersion of responses indicate that the scaling procedure is more efficient and consistent.

Based on elastic-perfectly-plastic and bilinear single-degree-of-freedom (SDF) systems, the accuracy, efficiency, and consistency of the ASCE/SEI 7 ground-motion scaling procedure are evaluated by applying it to 480 sets of groundmotions. The number of records in these sets varies from three to ten. The scaled records in each set were selected in three different ways: (i) randomly and (ii) minimizing discrepancy between scaled spectrum of a record and the target spectrum over the period range from $0.2 T_{n}$ to $1.5 T_{n}$ (this approach will be referred to as "Best1") and (iii) minimizing discrepancy between scaled spectrum of a record and the target spectrum over the period range from $0.2 T_{n}$ to $1.5 T_{n}$, and then the final set of records was identified with spectralacceleration values at $T_{n}$ close to that of the design spectrum (this approach will be referred to as "Best2").

\section{Ground-Motions Selected}

The thirty records selected for this investigation (listed in table 1) were recorded from seven shallow crustal earthquakes compatible with the following scenario:

- Moment magnitude: $M_{w}=6.7 \pm 0.2$

- Joyner-Boore distance: $R_{\mathrm{JB}}=25 \pm 5 \mathrm{~km}$

- NEHRP3 soil type: C and D

- Highest usable period $\geq 4 \mathrm{sec}$

Shown in figure 1 are the 5-percent-damped geometric-mean response spectra for the $x$ component (identified as the maximum horizontal component) of the unscaled ground-motions. The geometric-mean spectrum of thirty records is taken as the design spectrum (that is, target spectrum) for purposes of this investigation.

\footnotetext{
${ }^{3}$ National Earthquake Hazard Reduction Program
} 


\section{Description of Inelastic SDF Systems}

The structures considered are 16 SDF systems with vibration periods $T_{n}$ equal to $0.2,0.5,1$, and $2.5 \mathrm{sec}$, and yield strength reduction factors $R$ equal to $1,2,4$, and 8 . The design base shear is determined as the mass of the system (assumed to be $\left.1 \mathrm{kip}-\mathrm{sec}^{2} / \mathrm{in}\right)$ times the geometric-mean pseudo-acceleration at $T_{n}$ reduced by $R$. The damping ratio of the selected SDF systems is 5percent.

Two constitutive models, used for the inelastic SDF systems, are: (1) an elastic-perfectly-plastic model, and (2) a bilinear model with a strength hardening ratio of 10 percent.

\section{Methodology}

According to the ASCE/SEI 7 procedure for twodimensional (or planar) analyses of "regular" structures, the ground-motions should be scaled such that the mean value of the 5-percent-damped response spectra for the set of scaled motions is not less than the design spectrum over the period range from $0.2 T_{n}$ to $1.5 T_{n} \mathrm{sec}$. The ASCE/SEI 7 scaling procedure does not insure a unique scaling factor for each record; various combinations of scaling factors can be defined to insure that the mean spectrum of scaled records remains above the target spectrum over the specified period range. To achieve the desirable goal of scaling each record with a minimum scale factor closest to unity, we implemented the ASCE/SEI 7 scaling procedure for randomly selected ground-motions as follows:

1. For each of the thirty records listed in table 1, calculate the 5-percent-damped response spectrum $A(T)$ and the vector $\mathbf{A}$ of spectral values at 300 logarithmically spaced periods $T$ over the period range from $0.2 T_{n}$ to $1.5 T_{n} \mathrm{sec}$.

2. Obtain a target (that is, "design") pseudoacceleration spectrum $\hat{A}(T)$ as the geometricmean spectrum of thirty records. Define $\hat{A}$ as a vector of target spectral values $\hat{A}_{i}$ at periods $T$ over the period range from $0.2 T_{n}$ to $1.5 T_{n}$ sec.

3. Compute the scaling factor $\mathrm{SF}_{1}$ to minimize the difference between the target spectrum $\hat{A}(T)$ (Step 2) and the response spectrum $A(T)$ (Step 1) by solving the following minimization problem for each ground-motion:

$\min _{\mathrm{SF}_{1}}\left\|\log \hat{\mathbf{A}}-\mathrm{SF}_{1} \times \log \mathbf{A}\right\| \Rightarrow \mathrm{SF}_{1}$

where $\|\cdot\|$ is the Euclidean norm. Required for this purpose is a numerical method to minimize scalar functions of one variable; such methods are available in textbooks on numerical optimization (for example, Nocedal and Stephen, 2006). This minimization ensures that each scaled response spectrum is as close as possible to the target spectrum, as shown schematically in figure 2.

4. Randomly select a set of $m$ ground-motions to be used in nonlinear RHA of the systems described previously. No more than two records from the same event should be included in a single set, so that no single event is dominant within a set.

5. Determine the vector $\hat{\mathbf{A}}_{\text {scaled }}$ for the mean scaled spectrum defined as the mean of the scaled spectra $\left(\mathrm{SF}_{1} \times \mathbf{A}\right)$ of the set of $m$ records. The ordinates of this mean scaled spectrum could be smaller than the ordinates of the target spectrum at the same periods.

6. Calculate the maximum normalized difference $\varepsilon_{\text {ASCE }}$ (fig. 3a) between the target spectrum $\hat{\mathbf{A}}$ and the mean scaled spectrum $\hat{\mathbf{A}}_{\text {scaled }}$ over the period range from $0.2 T_{n}$ to $1.5 T_{n}$; that is, $\varepsilon_{\text {ASCE }}=\max _{0.2 T_{1} \leq T_{i} \leq 1.5 T_{1}}\left(\hat{A}_{i}-\hat{A}_{\text {scaled }, i}\right) \div \hat{A}_{i}$, where $\hat{A}_{i}$ and $\hat{A}_{\text {scaled, } i}$ are the ordinates of the target and the mean scaled pseudo-acceleration spectra 
at vibration period $T_{i}$, respectively. Define the scale factor $\mathrm{SF}_{2}=\left(1-\varepsilon_{\mathrm{ASCE}}\right)^{-1}$.

7. Determine the final scale factor $\mathrm{SF}=\mathrm{SF}_{1} \times \mathrm{SF}_{2}$ for each ground-motion.

Scaling ground-motions by the scaling factor $S F$ ensures that the mean value of the response spectra for the set of scaled motions is not less than the target spectrum over the period range from $0.2 T_{n}$ to $1.5 T_{n}$ (fig. $3 b$ ).

To select ground-motions using the approach "Best1", where the discrepancy between scaled spectrum of a record and the target spectrum over the period range from $0.2 T_{n}$ to $1.5 T_{n}$ is minimized, Step 4 is modified as follows:

4. Rank the scaled records based on their $\left\|\log \hat{\mathbf{A}}-\mathrm{SF}_{1} \times \log \mathbf{A}\right\|$ value; the record with the lowest value is ranked the highest. From the ranked list, select a set of $m$ records to be used in nonlinear RHA of the systems described previously.

Selection of ground-motions using the approach "Best2" requires that Steps 4-7 are iteratively implemented until the errors, defined as $\left\|\log \hat{\mathbf{A}}-\mathrm{SF}_{1} \times \log \mathbf{A}\right\|$ and $\left|A\left(T_{n}\right)-\mathrm{SF} \times A\left(T_{n}\right)\right|$, are minimized. At the end of Steps 1 to 7 , the scaling factors for the sets of $m$ ground-motions would have been determined. Nonlinear RHA is then used to obtain final EDP values. If at least seven ground-motions are analyzed $(m \geq 7)$, the design values of EDPs are taken as the mean or median $^{4}$ of the EDPs over the ground-motions used. If fewer than seven ground-motions are analyzed, the design values of EDPs are taken as the maximum values of the EDPs.

\footnotetext{
${ }^{4}$ Because the geometric mean and median of a lognormal distribution are the same, we decided to employ the term "median" instead of geometric mean, as is commonly done.
}

\section{Benchmark Inelastic Deformations}

Benchmark values of inelastic deformations $\left(D_{n}\right)$ were determined by using nonlinear RHA of the SDF systems described previously subjected to each of the 30 unscaled ground-motions, and computing the median and mean value of the data set.

Hancock and others (2008) noted that the empirical ground-motion models that are used to derive the target spectrum assume the groundmotions to be lognormally distributed; therefore, the use of the median response spectrum of the records as a target spectrum is more consistent with the specification of the target spectrum. Similarly, it commonly is assumed that EDPs are lognormally distributed (Cornell and others, 2002); for this reason, it is more appropriate to represent the "mean" structural response by the median, a conclusion that is widely accepted. However, the ASCE/SEI 7 procedure states that the mean values of EDPs are used if at least seven ground-motions are considered. We decided to use both the median and the mean of the inelastic deformations as the benchmark values. In all cases of benchmark computations, the mean is larger than the median of inelastic deformations, indicating that the distribution of $D_{n}$ is positively skewed. The percent differences between the two are in the ranges of 15 to 63,23 to 39,38 to 48 , and 42 to 63 for elastic-perfectly-plastic systems with $R$ equal to $1,2,4$, and 8 , respectively. For bilinear systems the percent differences are 11 to 26,12 to 32,20 to 45 , and 27 to 56 for the same R values. Note that the difference between mean and median increases with increasing $R$ value.

\section{Evaluation of ASCE/SEI 7 Scaling Procedure - Fewer Than Seven Ground- Motions}

The ASCE/SEI 7 scaling procedure was implemented for the inelastic SDF systems of this investigation subjected to one component of ground-motion (table 1). The accuracy of the ASCE/SEI 7 procedure was evaluated first by 
comparing the maximum value of the inelastic deformation $D_{n}$ due to seven sets of 3 to 6 scaled records against the benchmark value, defined as the median (or mean) value of $D_{n}$ due to the 30 unscaled ground-motions. These comparisons are shown in figures 4 and 5 for elastic-perfectly-plastic systems with $T_{n}=0.2,0.5,1$, and $2.5 \mathrm{sec}$, and $R=1$, 2,4 , and 8 due to groups of $3,4,5$, and 6 records called as G3, G4, G5 and G6, respectively. Seven sets of records were considered in each of these groups. Among these seven sets, the first five sets of records were selected randomly out of 30 records, and the two remaining sets of records were selected with the criteria explained previously; these are sets "Best1" and "Best2". For each $T_{n}, \mathrm{R}$, and constitutive model combinations, a total of 30 sets of records are utilized. For the benchmark, the blue dot and the vertical line represent the median deformation value plus and minus one standard deviation (henceforth denoted as $\pm \sigma$ ), assuming a lognormal distribution. For each set, the vertical line and the dot represent the range of the data set and maximum deformation value, respectively. Similar plots are presented in figures 6 and 7 for bilinear systems. Figures 4 and 5 permit the following observations: (1) Increasing the number of records from 3 to 6 has a minor effect in the accuracy of the procedure; overestimations range from 1 to 1500 percent and from 35 to 820 percent for groups $\mathrm{G} 3$ and G6, respectively. (2) The accuracy of the procedure decreases with increasing $R$ value and decreasing period; the maximum error increases from 250 to 1,060 percent and from 620 to 1,500 percent if $R$ changes from 1 to 8 , and $T_{n}$ changes from 2.5 to $0.2 \mathrm{sec}$, respectively. (3) The improvement gained by the use of sets "Best1" and "Best2" is marginal. For $R$ equals 8 , the errors range from 10 to 190 percent and from 0.2 to 1,130 percent for sets Best1 and Best2, respectively. For bilinear systems, the errors are slightly smaller than those for elastic-perfectly-plastic systems.

The benchmark results shown in figures 4 through 7 are based on the median deformation value; figure 8 compares the benchmark, calculated as the mean of $30 D_{n}$ values, and the
ASCE/SEI 7 deformation values for elasticperfectly-plastic and bilinear systems. Included also are the horizontal lines at 0.8 and 1.2 times the benchmark to indicate \pm 20 percent error around the "true" value. It is apparent that the ASCE/SEI 7 scaling procedure is not accurate and overly conservative, especially for elastic-perfectly-plastic systems. Insignificant improvement is gained by the use of sets "Best1" and "Best2".

Figures 9 and 10 show intra- and inter-set dispersion values to assess, respectively, the efficiency and consistency of the ASCE/SEI 7 procedure. A lognormal distribution of $D_{n}$ values was assumed. As shown in figure 9, the intra-set dispersion increases with increasing period; implying that the procedure becomes less efficient. Similarly, inter-set dispersion increases with increasing $R$ (fig. 10), indicating that the procedure becomes less consistent. Note that the inter-set dispersion tends to decrease with increasing number of records per set. According to the results presented in figures 4 through 10, the accuracy, efficiency, and consistency in the estimation of inelastic deformations are not achieved in the ASCE/SEI 7 procedure if fewer than seven records are employed. The procedure was found to be unacceptably conservative and unstable.

\section{Evaluation of ASCE/SEI 7 Scaling Procedure - Seven or More Ground- Motions}

The accuracy of the ASCE/SEI 7 procedure was evaluated next by comparing the median (or mean) value of the inelastic deformation $D_{n}$ due to seven sets of 7 to 10 scaled records against the benchmark value, defined as the median (or mean) value of $D_{n}$ due to the 30 unscaled groundmotions.

Figures 11 and 12 show the range of inelastic deformation values $D_{n}$ for elastic-perfectly-plastic systems due to groups of $7,8,9$, and 10 records called G7, G8, G9, and G10, respectively. As explained previously, seven sets were considered in each of these groups (that is, a total of 28 sets 
plus sets Best1 and Best2 for each $T_{n}, \mathrm{R}$ and constitutive-model combinations). The dot and the vertical line represent the median deformation value $\pm \sigma$ assuming a lognormal distribution. Similar plots are presented in figures 13 and 14 for bilinear systems. Figures 15 and 16 compare the benchmark with the ASCE/SEI 7 deformation values for elastic-perfectly-plastic and bilinear systems for a range of $R$ values. The ASCE/SEI 7 results in figure 15 are the median of $7,8,9$, and $10 D_{n}$ values from scaled records, and the benchmark is defined as the median of $30 D_{n}$ values from unscaled records, whereas in figure 16 , mean values are used for both the ASCE/SEI 7 and the benchmark results. Included also in these figures are the lines at 0.8 and 1.2 times the benchmark to represent \pm 20 percent error around the "true" value. By comparing figure 8 with figure 16 , it becomes obvious that the ASCE/SEI 7 scaling procedure utilizing seven or more randomly selected records provides a more accurate estimate of inelastic deformations. However, the overestimations in median values of inelastic deformation generally are larger than 20 percent, especially for $R=4$ and 8 , as shown in figure 17 . Figures 11, 12, and 15 permit the following observations: (1) increasing the number of records from 7 to 10 has a minor effect in the accuracy of the procedure; overestimations range from 0.5 to 140 percent and from 0.6 to 124 percent for groups G7 and G10, respectively. (2) The accuracy of the procedure decreases with increasing $R$ value; the maximum error increases from 56 to 140 if the $R$ value changes from 1 to 8 . (3) The fundamental period $T_{n}$ does not affect significantly the accuracy of the ASCE/SEI 7 procedure if the records are selected randomly. The maximum error is 140 and 134 percent for $T_{n}=0.2$ and $2.5 \mathrm{sec}$, respectively. Figures 13,14, and 16 lead to similar conclusions.

For short periods and large $R$ values, the mean of randomly selected sets is not similar to the mean of the benchmark data set as demonstrated by the analysis of variance (ANOVA) values in figure 18. The ANOVA test returns the $p$ value under the null hypothesis that both ASCE/SEI 7 and benchmark results are drawn from populations with the same mean. If $p$ is near zero, it questions the null hypothesis and suggests that the ASCE/SEI 7 mean is significantly different from the benchmark mean. This statistical test indicates that the random selection of records for the ASCE/SEI 7 procedure may lead to inconsistent results.

For systems with $T_{n} \geq 0.5 \mathrm{sec}$ or small $\mathrm{R}$ values, set "Best2" is more accurate than set "Best1", demonstrating that consideration of spectral shape and $A\left(T_{n}\right)$ in selecting and scaling ground-motions improves the $D_{n}$ estimates significantly (Figs. 1118). For $T_{n}=2.5 \mathrm{sec}$, the error of the procedure ranges from 9 to 60 percent and from 3 to 30 percent for sets "Best1" and "Best2", respectively. For systems with very short periods $\left(T_{n}=0.2 \mathrm{sec}\right)$ and large $R$ values ( $R=4$ and 8$)$, both sets "Best 1 " and "Best 2" lead to inaccurate estimates of inelastic deformations (figs. 11-18); overestimations exceed 100 percent due to the high variability of spectral pseudo-accelerations and large discrepancies between elastic and inelastic spectra for periods in the acceleration sensitive region and large $R$ values.

The intra- and inter-set dispersion values are shown next in figures 19 and 20, where a lognormal distribution of $D_{n}$ values was assumed. The intra-set dispersion increases with increasing period, indicating larger variability of response values within a set. Similarly, the inter-set dispersion increases with increasing $R$ values, implying that larger inelastic deformations would lead to increased set-to-set variability. As expected, the inter-set dispersion tends to decrease with increasing number of records per set. By comparing figures 10 and 20, it becomes evident that utilizing seven or more randomly selected records in the ASCE/SEI 7 reduces the inter-set dispersion significantly; the reduction is more pronounced for elastic-perfectly-plastic systems. The reduced inter-set variability indicates the consistency in the benchmark estimates of the ASCE/SEI 7 procedure using different sets. For systems with a fundamental period in the velocity or displacement sensitive region, accuracy, efficiency, and consistency are achieved only if 
records are selected on the basis of their spectral shape and $A\left(T_{n}\right)$ as opposed to random selection.

\section{Modal-Pushover-Based Scaling Procedure - Alternative to the ASCE/SEI 7 Scaling Procedure}

Because the ASCE/SEI 7 ground-motion scaling method does not consider explicitly the inelastic behavior of the structure, it may not be appropriate for structures with short periods or for structures located in near-field sites where the inelastic deformation can be significantly larger than the deformation of the corresponding linear system. For such cases, scaling methods that are based on the inelastic deformation spectrum, or methods that consider the response of the first-"mode" inelastic SDF system, are more appropriate (Luco and Cornell 2007, Tothong and Cornell 2008, PEER 2009). Kalkan and Chopra (2010a,b and 2011a,b) used these concepts to develop a modal pushoverbased scaling (MPS) procedure for selecting and scaling earthquake ground-motion records in a form convenient for evaluating existing structures and proposed designs of new structures. This procedure explicitly considers structural strength, determined from the first-"mode" pushover curve, and determines a scaling factor for each record to match a target value of the deformation of the first"mode" inelastic SDF system. If the MPS procedure were applied to the systems of this investigation, it would lead to null error in the estimation of inelastic deformations and null intra- and inter-set dispersions. Therefore, the MPS procedure for SDF systems would be absolutely accurate, efficient and consistent.

\section{Conclusions}

Based on elastic-perfectly-plastic and bilinear inelastic single-degree-of-freedom systems, the accuracy, efficiency, and consistency of the ASCE/SEI 7 ground-motion scaling procedure are examined by comparing the median and mean values of the inelastic deformation due to 480 sets of scaled records against benchmark values. The number of records in these sets varies from three to ten. The records in each set were selected either (i) randomly, (ii) considering their spectral shapes or (iii) considering the design spectral-acceleration value $A\left(T_{n}\right)$ in addition to their spectral shapes. This evaluation of the ASCE/SEI procedure has led to the following conclusions:

1. The ASCE/SEI 7 scaling procedure does not insure a unique scaling factor for each record; various combinations of scaling factors can be defined to insure that the mean spectrum of scaled records remains above the target spectrum over the specified period range. Utilizing a minimum scale factor closest to unity for each record may overcome this flaw in the ASCE/SEI 7 scaling procedure.

2. The ASCE/SEI 7 procedure is found to be conservative; it is neither efficient nor consistent if fewer than seven groundmotions are utilized. Only marginal improvements were gained by selecting and scaling records based on their spectral shape (as in sets Best1) and design spectral-acceleration value, $A\left(T_{n}\right)$ (as in sets Best2).

3. The ASCE/SEI 7 scaling procedure utilizing seven or more randomly selected records provides more accurate estimates of inelastic deformations. However, the overestimations in median values of inelastic deformation generally are larger than 20 percent. Increasing the number of records from 7 to 10 has a minor effect in the accuracy of the procedure. Thus, use of 7 records is found to be sufficient.

4. In general, the accuracy of the procedure decreases with increasing $R$ value. The fundamental period, $T_{n}$, (that is, long or short periods) does not significantly affects its accuracy if the records are selected randomly.

5. For systems with $T_{n} \geq 0.5 \mathrm{sec}$ or small $\mathrm{R}$ values $(R<4)$, consideration of spectral 
shape and $A\left(T_{n}\right)$ in selecting and scaling ground-motions improves the displacement response $\left(D_{n}\right)$ estimates significantly. For systems with very short periods $\left(T_{n}=0.2\right.$ sec) and large $R$ values ( $R=4$ and 8$)$ however, both sets "Best 1" and "Best 2" lead to inaccurate estimates of inelastic deformations with overestimations exceeding 100 percent. This is due to the high variability of spectral pseudoacceleration values, large discrepancies between elastic and inelastic spectra for periods in the acceleration-sensitive region and large $R$ values (that is, increased inelastic response). For such cases, scaling methods that are based on the inelastic deformation spectrum, or that consider the response of the first-"mode" inelastic SDF system, are more appropriate.

This study has focused on the statistical examination of the required number of records for the ASCE/SEl ground-motion scaling method, which has been limited to elastic-perfectly-plastic and bilinear inelastic single-degree-of-freedom systems.

\section{Acknowledgments}

Juan C. Reyes would like to acknowledge the generous support of Universidad de los Andes for providing him the financial support for his stay at the U.S. Geological Survey, Menlo Park. Special thanks are extended to Anil K. Chopra, Charlie Kircher and Nico Luco for providing their valuable comments and suggestions, which help improving the technical quality of this report.

\section{References Cited}

ASCE, 2005, Minimum design loads for buildings, ASCE/SEI 7-05, Reston, VA.

ASCE, 2010, Minimum design loads for buildings and other structures, ASCE/SEI 7-10, Reston, VA.

Cornell, C.A., Jalayer, F., Hamburger, R.O., and Foutch, D.A., 2002, Probabilistic basis for 2000 SAC federal emergency management agency steel moment frame guidelines, Journal of Structural Engineering (ASCE); v. 128, no. 4, p. 526-533.

Hancock, J., Bommer, J., and Stafford, J., 2008, Numbers of scaled and matched accelerograms required for inelastic dynamic analyses, Earthquake Engineering and Structural Dynamics, v. 37, p. 1585-1607.

International Conference of Building Officials (ICBO), 2006, International Building Code, Whittier, CA.

International Conference of Building Officials (ICBO), 2007, California Building Code, Whittier, CA.

Kalkan, E., and Chopra, A.K., 2010a, Practical Guidelines to Select and Scale Earthquake Records for Nonlinear Response History Analysis of Structures, USGS Open File Report 2010-1068, 126 p. (http://pubs.usgs.gov/of/2010/1068/).

Kalkan, E., and Chopra, A.K., 2010b, Evaluation of Modal pushover-based scaling of one component of ground-motion: Tall buildings, Earthquake Spectra (submitted for publication; http://nsmp.wr.usgs.gov/ekalkan/PDFs/Papers/J33 _Kalkan_Chopra.pdf).

Kalkan, E., and Chopra, A.K., 2011a, Modal-pushoverbased ground-motion scaling procedure, Journal of Structural Engineering (ASCE), v. 138, no. 3, p. 289-310 (http://nsmp.wr.usgs.gov/ekalkan/PDFs/Papers/J25 _Kalkan_Chopra.pdf).

Kalkan, E., and Kwong, N.S., 2011b, Documentation for Assessment of Modal Pushover-based Scaling Procedure for Nonlinear Response History Analysis of "Ordinary Standard" Bridges, U.S. Geological Survey Open-File Report 2010-1328, 56 p. (http://pubs.usgs.gov/of/2010/1328/).

Luco, N., and Cornell, A.C., 2007, Structure-specific scalar intensity measures for near-source and ordinary earthquake ground-motions, Earthquake Spectra, v. 23, n. 2, p. 357-392.

Nocedal, J., and Stephen, J.W., 2006, Numerical optimization, 2nd ed.: Springer Series in Operations Research, Springer, USA.

PEER Ground-Motion Selection and Modification Working Group, 2009, Evaluation of Ground-Motion Selection and Modification Methods: Predicting Median Interstory Drift Response of Buildings", 
Haselton, C. B. (editor). PEER Report 2009/01, University of California, Berkeley, CA.

Tothong, P., and Cornell, A.C., 2008, Structural performance assessment under near-source pulse- like ground-motions using advanced ground-motion intensity measures, Earthquake Engineering and Structural Dynamics, v.37, no. 7, p. 1013-1037.

\section{Notation}

The following symbols are used in this report:

$\begin{array}{ll}A(T) & \text { Pseudo-spectral-acceleration at period } T \\ \mathbf{A} & \text { Vector of pseudo-spectral-acceleration values } \\ \hat{A}(T) & \text { Target value of pseudo-spectral-acceleration at period } T \\ \hat{\mathbf{A}} & \text { Vector of target pseudo-spectral-acceleration values } \\ \hat{\mathbf{A}}_{\text {scaled }} & \text { Mean scaled spectrum of } m \text { records } \\ \varepsilon_{\text {ASCE }} & \text { Maximum normalized difference between target and mean scaled spectrum } \\ m & \text { Number of ground-motion records } \\ M_{w} & \text { Moment magnitude } \\ \mathrm{R} & \text { Yield-strength reduction factor } \\ R_{J B} & \text { Joyner-Boore distance-perpendicular distance to surface projection of fault plane } \\ \mathrm{SF} & \text { Ground motion scaling factor } \\ T_{n} & \text { Period of single-degree-of-freedom system; or elastic first-"mode" vibration period of structure } \\ V_{S 30} & \text { Average shear-wave velocity within } 30 \mathrm{~m} \text { depth from surface } \\ \sigma & \text { Standard deviation }\end{array}$


Table 1. Selected near-fault ground-motion records. [NEHRP, National Earthquake Hazard Reduction Program; AS, aftershock]

\begin{tabular}{|c|c|c|c|c|c|c|c|}
\hline $\begin{array}{l}\text { Record } \\
\text { sequence } \\
\text { number }\end{array}$ & Earthquake name & Year & Station Name & $\begin{array}{l}\text { Earthquake } \\
\text { magnitude } \\
\left(\mathrm{M}_{\mathrm{w}}\right)\end{array}$ & $\begin{array}{l}\text { Joyner-Boore } \\
\text { distance (km) }\end{array}$ & $\begin{array}{l}\text { NEHRP site } \\
\text { class }\end{array}$ & $\begin{array}{l}\text { Highest } \\
\text { usable } \\
\text { period (sec.) }\end{array}$ \\
\hline 1 & San Fernando, Calif. & 1971 & LA - Hollywood Stor FF & 6.6 & 22.8 & D & 4 \\
\hline 2 & San Fernando, Calif. & 1971 & Santa Felita Dam (Outlet) & 6.6 & 24.7 & C & 8 \\
\hline 3 & Imperial Valley (AS), Calif. & 1979 & Calipatria Fire Station & 6.5 & 23.2 & D & 8 \\
\hline 4 & Imperial Valley (AS), Calif. & 1979 & Delta & 6.5 & 22.0 & $D$ & 16 \\
\hline 5 & Imperial Valley (AS), Calif. & 1979 & El Centro Array \#1 & 6.5 & 19.8 & $D$ & 8 \\
\hline 6 & Imperial Valley (AS), Calif. & 1979 & El Centro Array \#13 & 6.5 & 22.0 & $D$ & 4 \\
\hline 7 & Imperial Valley (AS), Calif. & 1979 & Superstition Mtn Camera & 6.5 & 24.6 & C & 8 \\
\hline 8 & Irpinia, Italy & 1980 & Brienza & 6.9 & 22.5 & C & 4 \\
\hline 9 & Superstition Hills (AS), Calif. & 1987 & Wildlife Liquef. Array & 6.5 & 23.9 & $D$ & 8 \\
\hline 10 & Loma Prieta, Calif. & 1989 & Agnews State Hospital & 6.9 & 24.3 & $D$ & 4 \\
\hline 11 & Loma Prieta, Calif. & 1989 & Anderson Dam (Downstream) & 6.9 & 19.9 & C & 4 \\
\hline 12 & Loma Prieta, Calif. & 1989 & Anderson Dam (L Abut) & 6.9 & 19.9 & C & 8 \\
\hline 13 & Loma Prieta, Calif. & 1989 & Coyote Lake Dam (Downst) & 6.9 & 20.4 & $D$ & 8 \\
\hline 14 & Loma Prieta, Calif. & 1989 & Coyote Lake Dam (SW Abut) & 6.9 & 20.0 & C & 8 \\
\hline 15 & Loma Prieta, Calif. & 1989 & Gilroy Array \#7 & 6.9 & 22.4 & D & 4 \\
\hline 16 & Loma Prieta, Calif. & 1989 & Hollister - SAGO Vault & 6.9 & 29.5 & C & 8 \\
\hline 17 & Northridge, Calif. & 1994 & Castaic - Old Ridge Route & 6.7 & 20.1 & C & 8 \\
\hline 18 & Northridge, Calif. & 1994 & Glendale - Las Palmas & 6.7 & 21.6 & C & 6 \\
\hline 19 & Northridge, Calif. & 1994 & LA - Baldwin Hills & 6.7 & 23.5 & D & 6 \\
\hline 20 & Northridge, Calif. & 1994 & LA - Centinela St & 6.7 & 20.4 & D & 4 \\
\hline 21 & Northridge, Calif. & 1994 & LA - Cypress Ave & 6.7 & 29.0 & C & 4 \\
\hline 22 & Northridge, Calif. & 1994 & LA - Fletcher Dr & 6.7 & 25.7 & C & 5 \\
\hline 23 & Northridge, Calif. & 1994 & LA - N Westmoreland & 6.7 & 23.4 & D & 4 \\
\hline 24 & Northridge, Calif. & 1994 & LA - Pico \& Sentous & 6.7 & 27.8 & $D$ & 5 \\
\hline 25 & Kobe, Japan & 1995 & Abeno & 6.9 & 24.9 & $\mathrm{D}$ & 16 \\
\hline 26 & Kobe, Japan & 1995 & Kakogawa & 6.9 & 22.5 & D & 8 \\
\hline 27 & Kobe, Japan & 1995 & Morigawachi & 6.9 & 24.8 & $D$ & 10 \\
\hline 28 & Kobe, Japan & 1995 & OSAJ & 6.9 & 21.4 & $D$ & 16 \\
\hline 29 & Kobe, Japan & 1995 & Sakai & 6.9 & 28.1 & D & 8 \\
\hline 30 & Kobe, Japan & 1995 & Yae & 6.9 & 27.8 & D & 16 \\
\hline
\end{tabular}




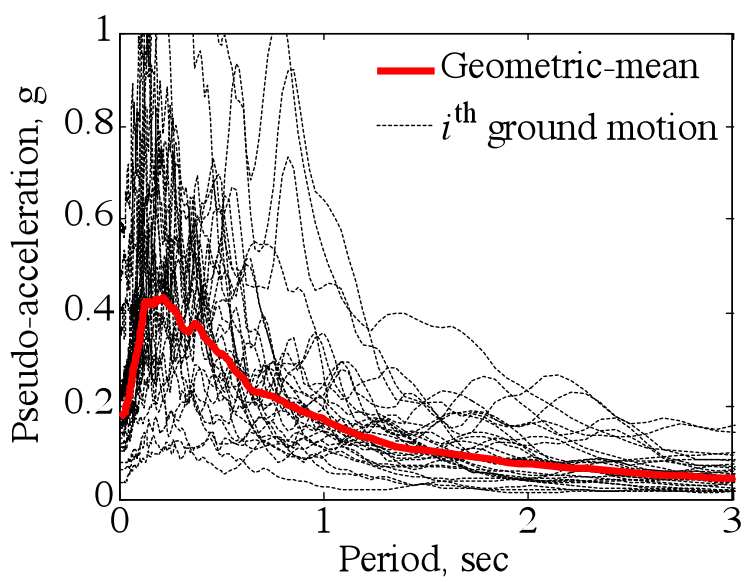

Figure 1. Response spectra of thirty near-fault ground-motions and their geometric-mean (that is, median) used as the target (that is, "design") spectrum for evaluation of the ASCE/SEI 7 ground-motion scaling procedure. Damping ratio 5-percent. 
(a)

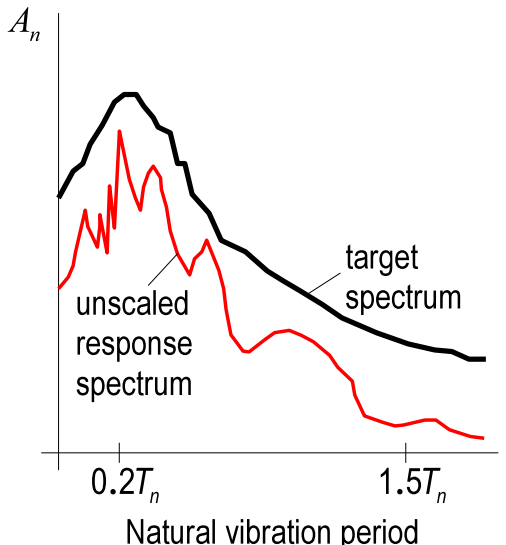

(b)

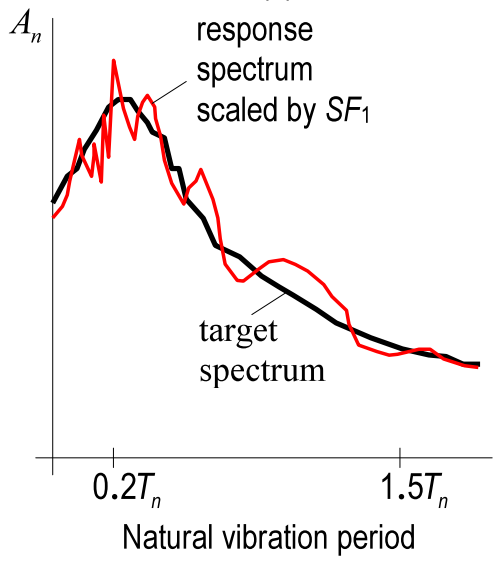

Figure 2. Schematic illustration of Step 3 of the evaluation methodology.

(a)

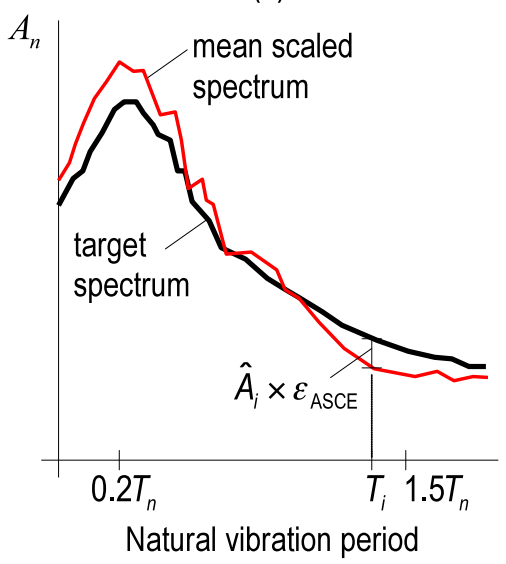

(b)

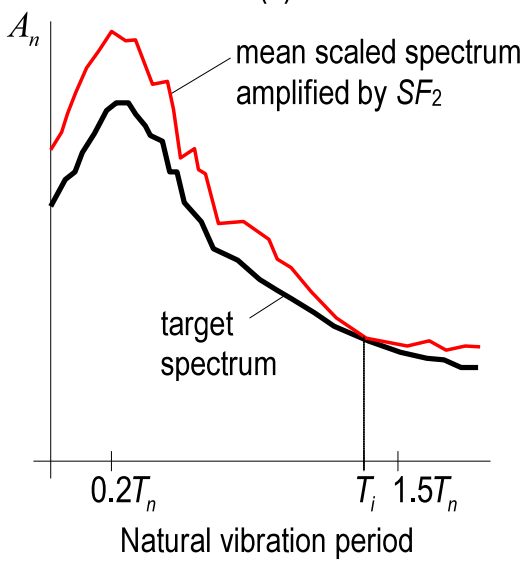

Figure 3. Schematic illustration of Step 6 of the evaluation methodology. 

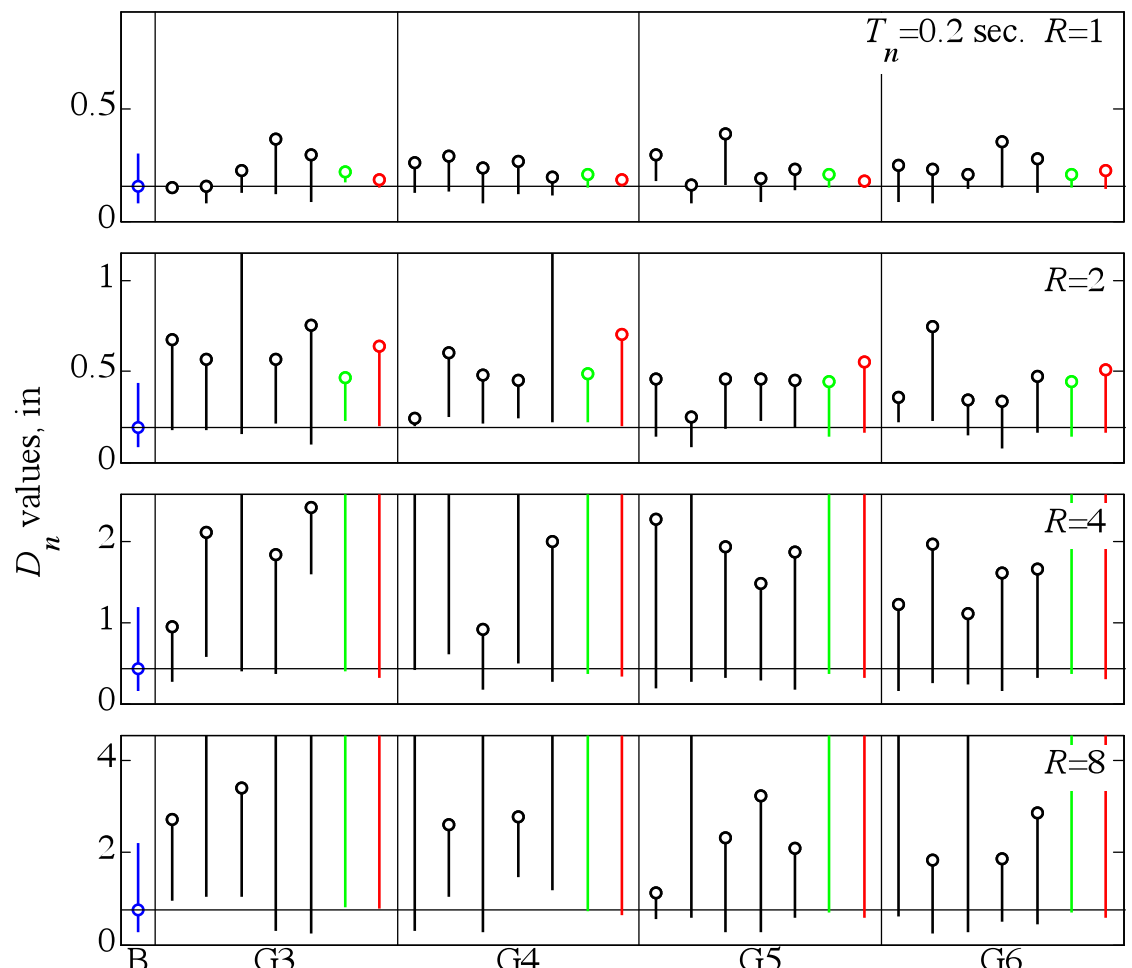

--Benchmark

- Set $i$

- Best1

$\rightarrow$ Best2
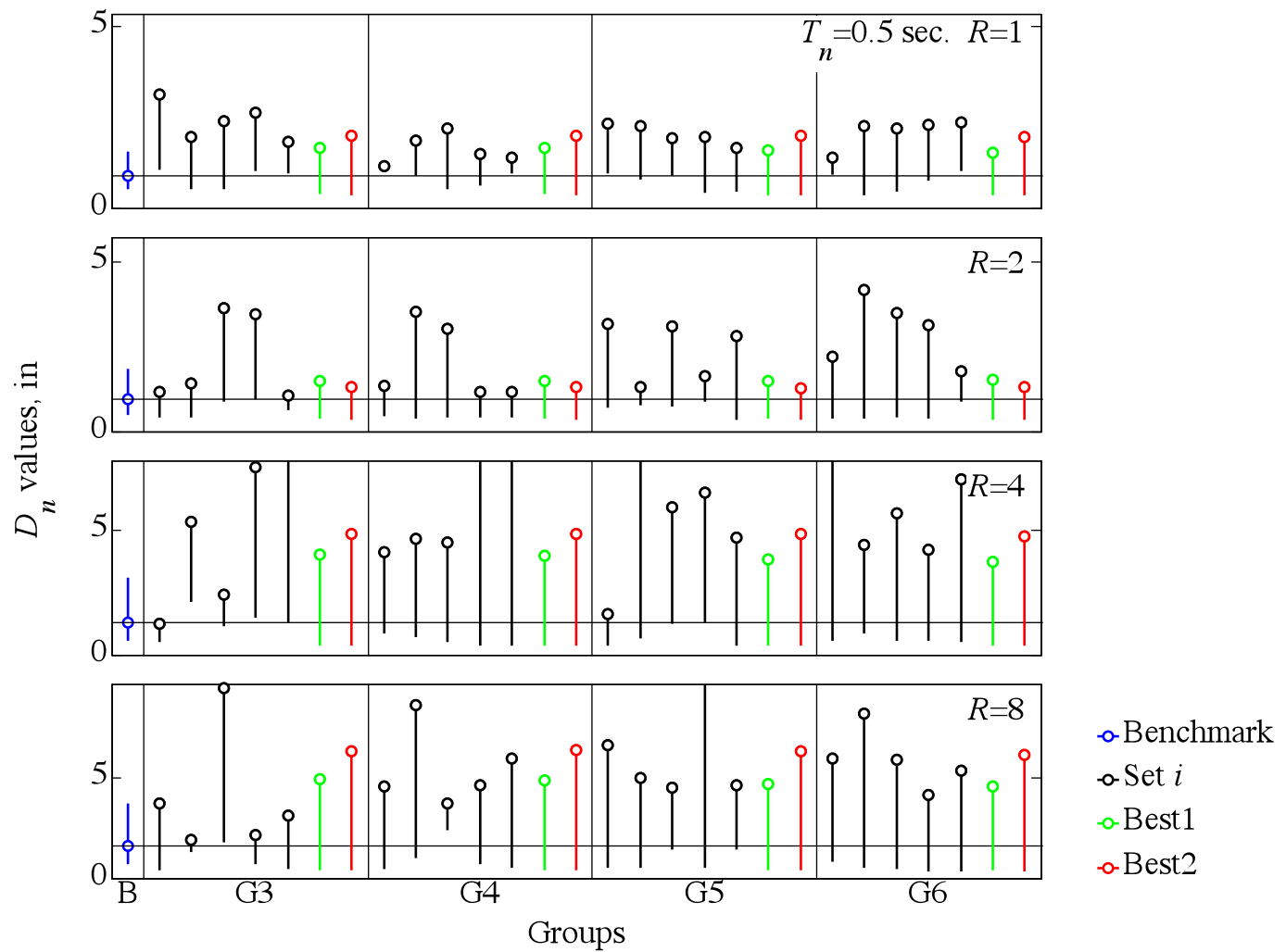

Figure 4. Range of inelastic deformation values for elastic-perfectly-plastic systems with $T_{n}=0.2 \mathrm{sec}$ (top four panels) and $T_{n}=0.5 \mathrm{sec}$ (bottom four panels), and $\mathrm{R}=1,2,4$, and 8 for sets of 3, 4, 5, and 6 records denoted respectively as G3, G4, G5, and G6. The blue dot and the vertical line represent the benchmark (denoted as $\mathrm{B}$ ) median deformation value $\pm \sigma$ assuming a lognormal distribution. For each set, the vertical line and the dot represent the range of the data set and maximum deformation value, respectively. 

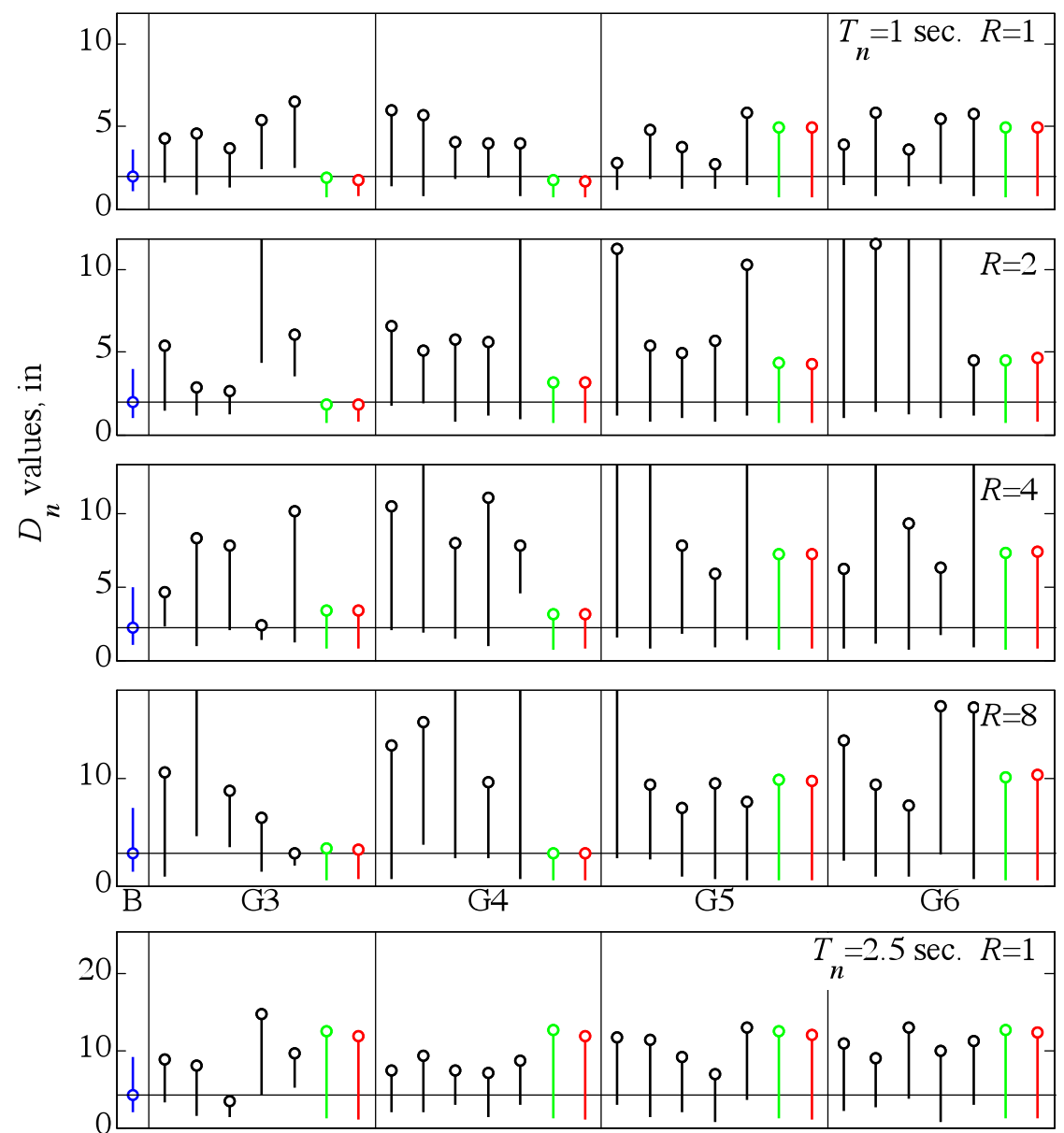

- Benchmark

- Set $i$

-Best1

$\rightarrow$ Best2
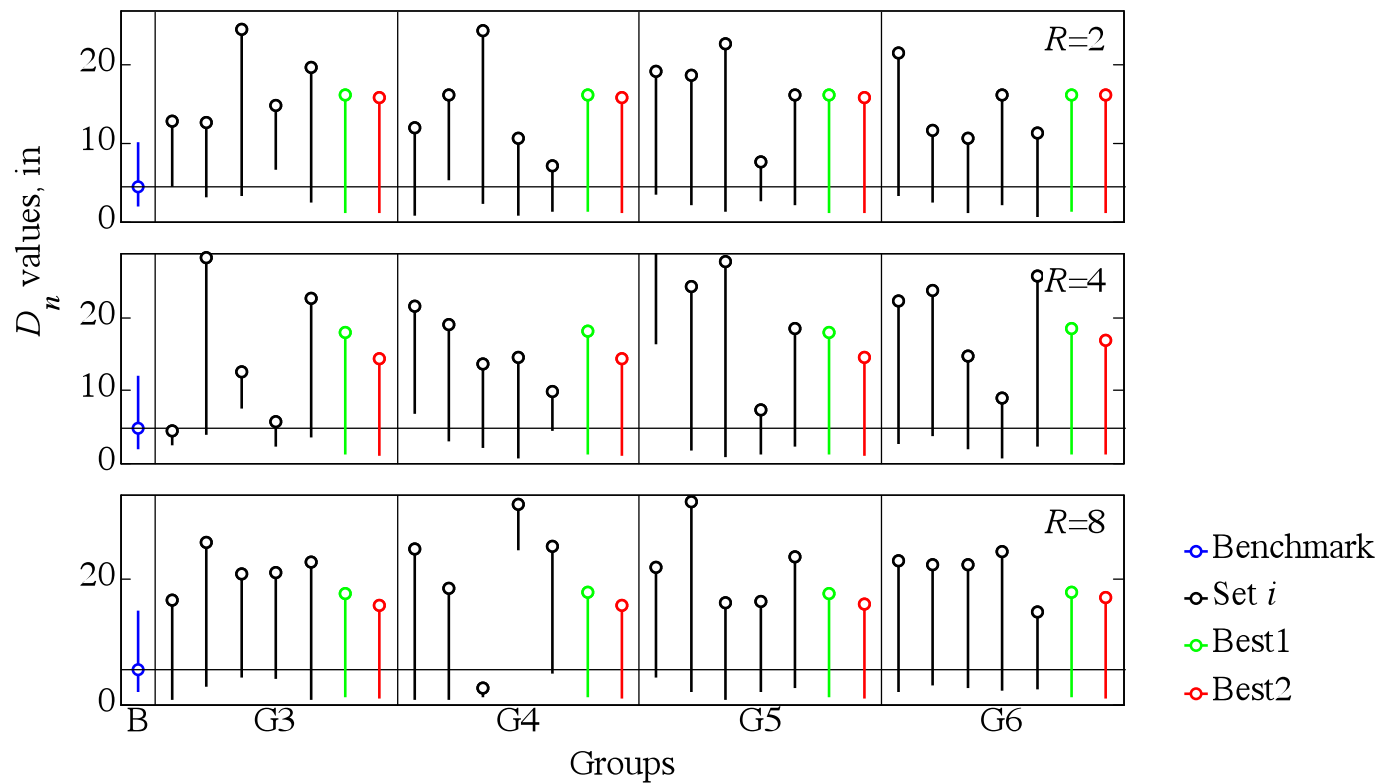

Figure 5. Range of inelastic deformation values for elastic-perfectly-plastic systems with $T_{n}=1 \mathrm{sec}$ (top four panels) and $T_{n}=2.5 \mathrm{sec}$ (bottom four panels), and $\mathrm{R}=1,2,4$, and 8 for sets of $3,4,5$, and 6 records denoted respectively as G3, G4, G5, and G6. The blue dot and the vertical line represent the benchmark (B) median deformation value $\pm \sigma$ assuming a lognormal distribution. For each set, the vertical line and the dot represent the range of the data set and maximum deformation value. 

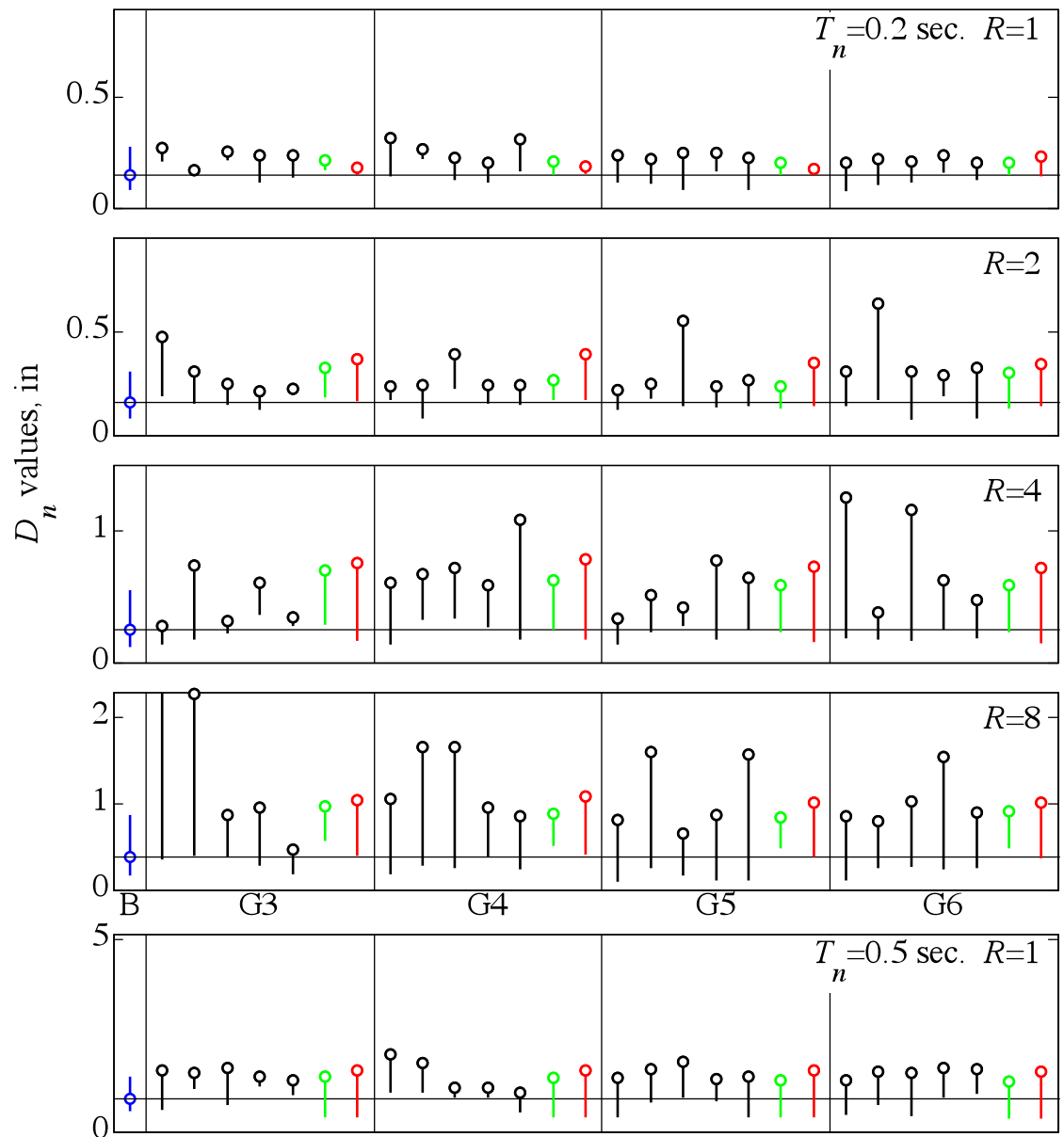

- Benchmark

- Set $i$

- Best1

$\cdots$ Best2
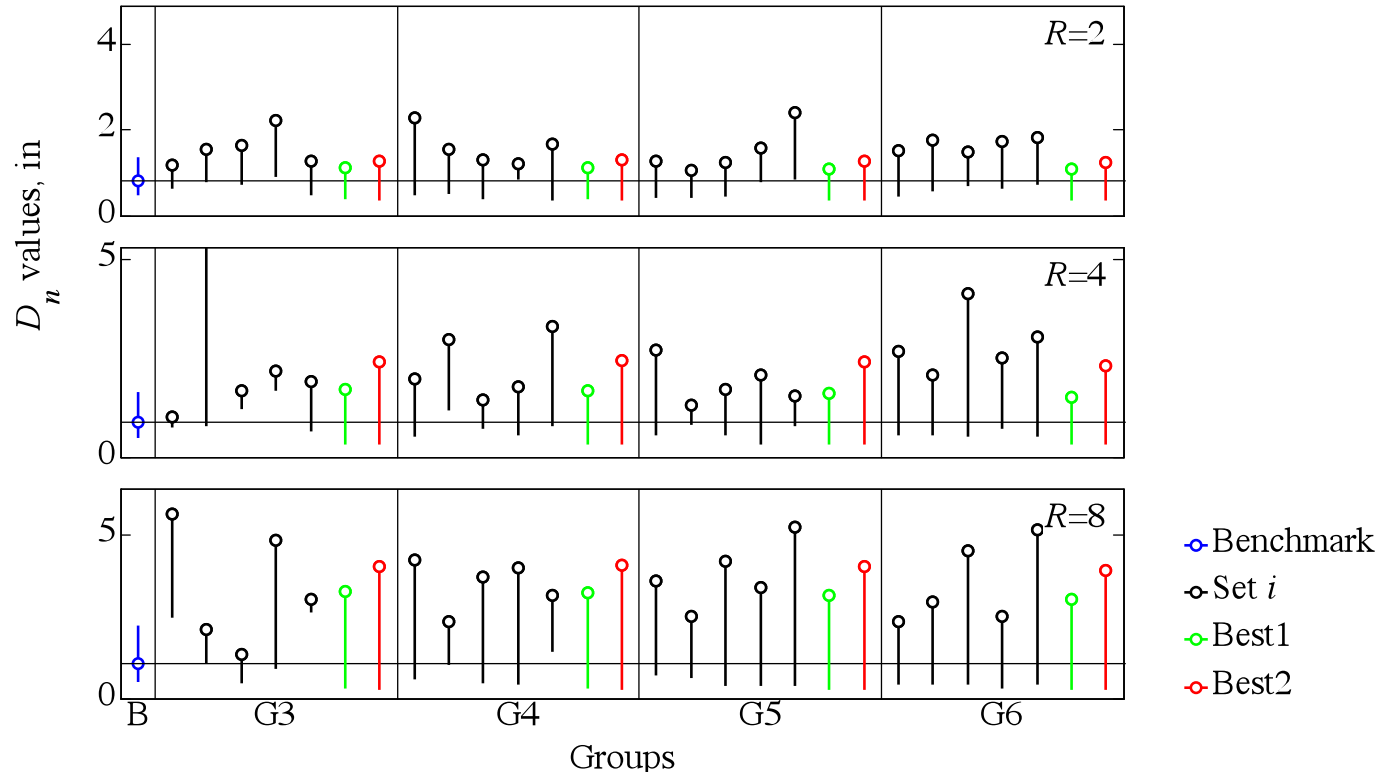

Figure 6. Range of inelastic deformation values for bilinear systems with $T_{n}=0.2 \mathrm{sec}$ (top four panels) and $T_{n}=0.5$ sec (bottom four panels), and $\mathrm{R}=1,2,4$, and 8 for sets of $3,4,5$, and 6 records denoted respectively as G3, G4, G5, and G6. The blue dot and the vertical line represent the benchmark (B) median deformation value $\pm \sigma$ assuming a lognormal distribution. For each set, the vertical line and the dot represent the range of the data set and maximum deformation value, respectively. 

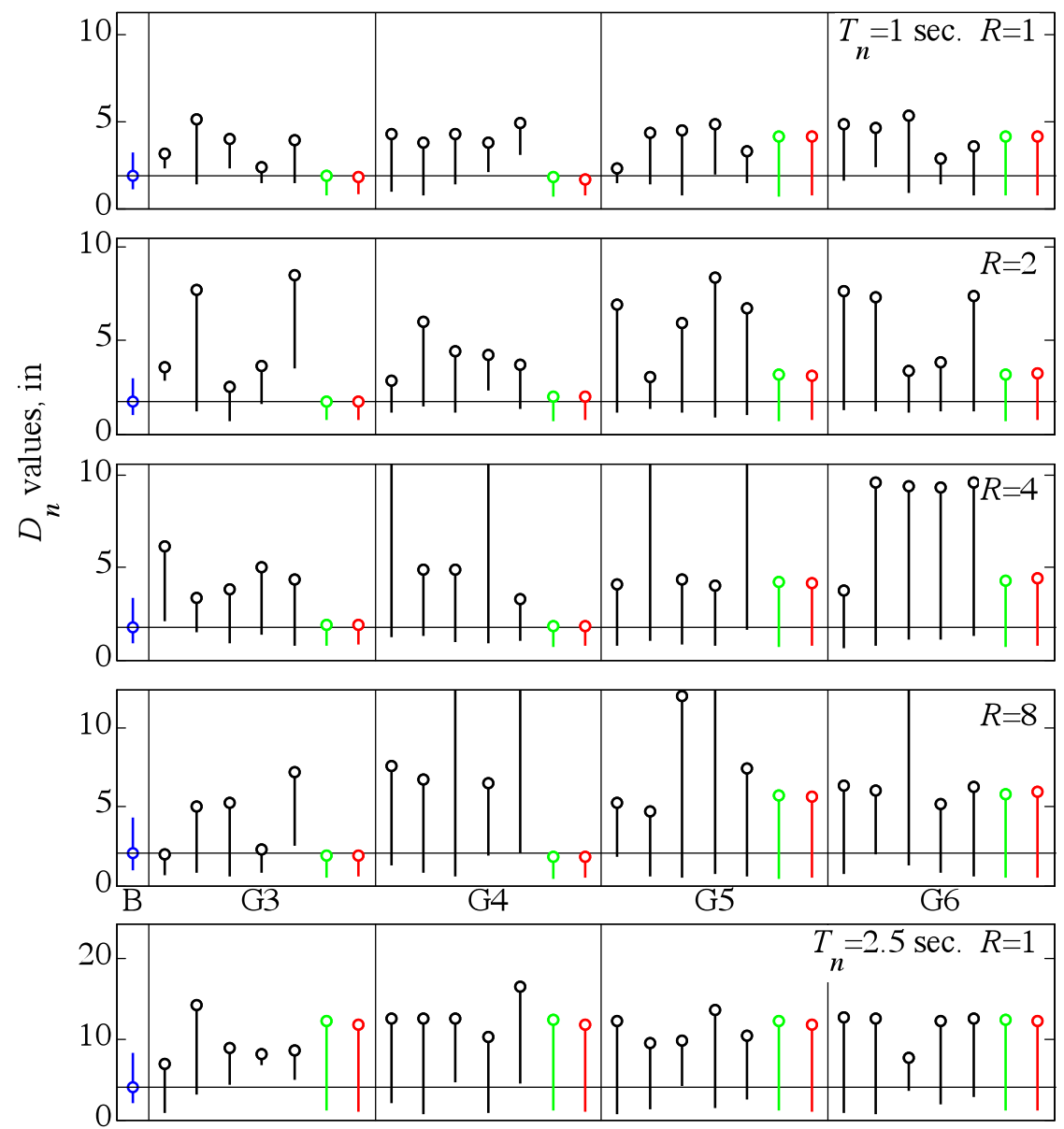

- - Benchmark

- Set $i$

-Best1

-Best2
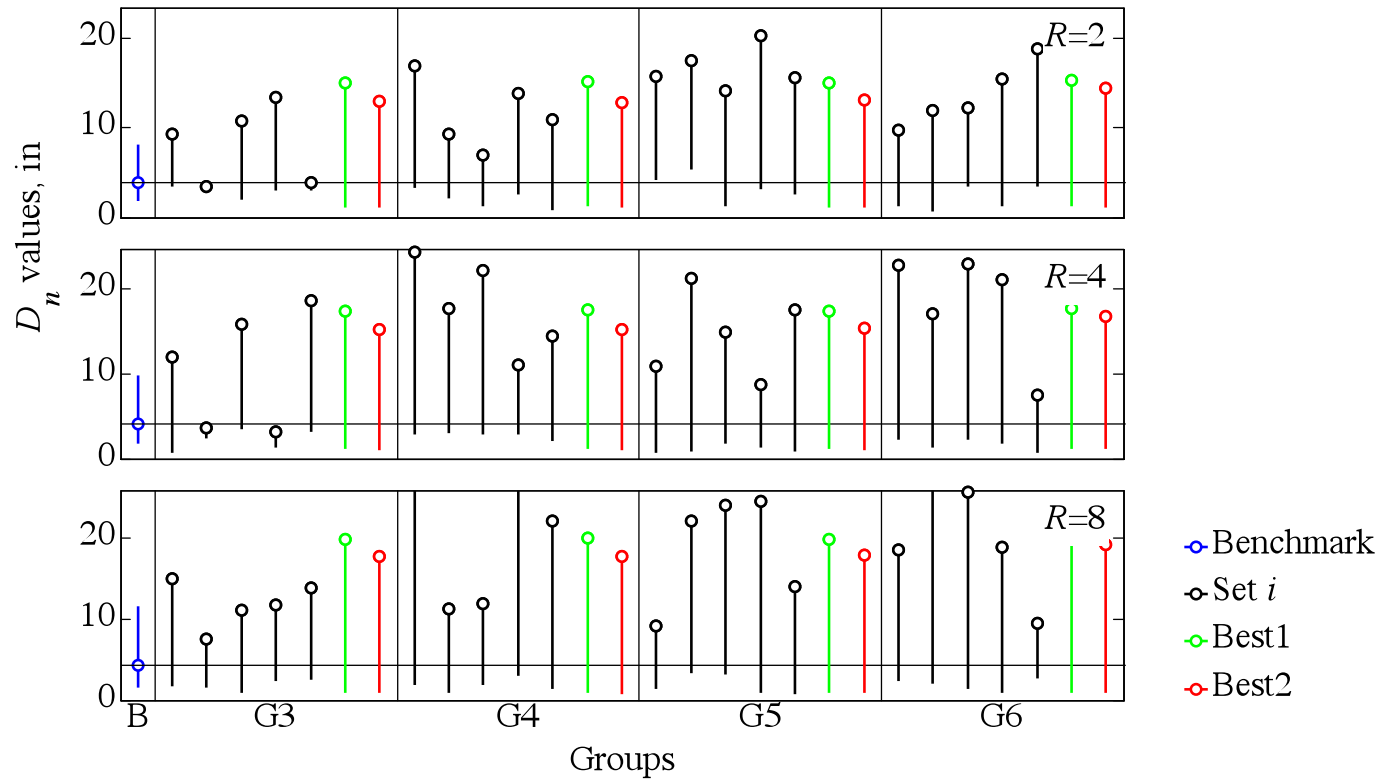

Figure 7. Range of inelastic deformation values for bilinear systems with $T_{n}=1 \mathrm{sec}$ (top four panels) and $T_{n}=2.5$ sec (bottom four panels), and $\mathrm{R}=1,2,4$, and 8 for sets of $3,4,5$, and 6 ground-motion records denoted respectively as $\mathrm{G} 3, \mathrm{G} 4, \mathrm{G} 5$, and $\mathrm{G} 6$. The blue dot and the vertical line represent the benchmark (B) median deformation value $\pm \sigma$ assuming a lognormal distribution. For each set, the vertical line and the dot represent the range of the data set and maximum deformation value, respectively. 
(a) Elastic-perfectly-plastic systems

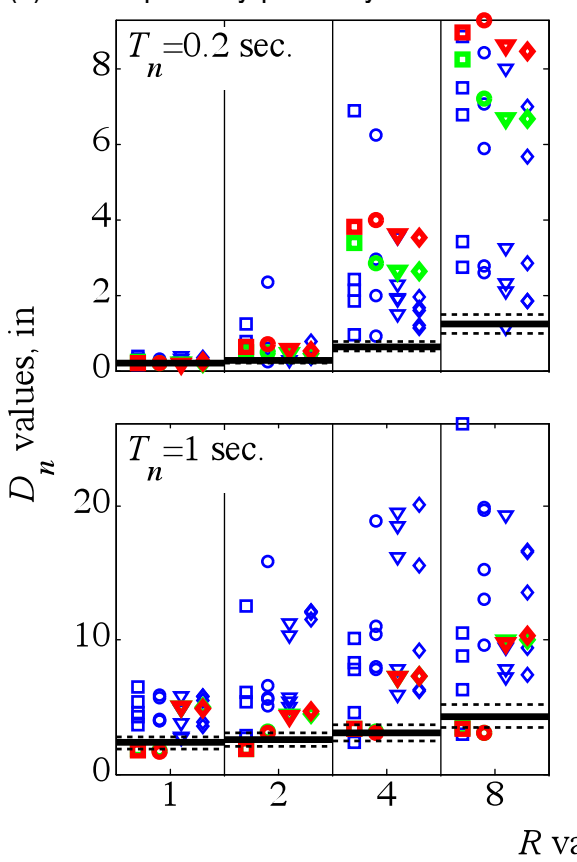

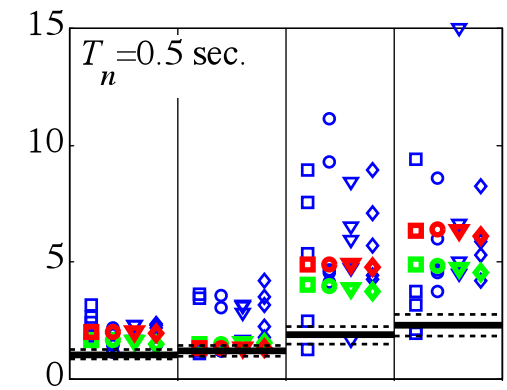

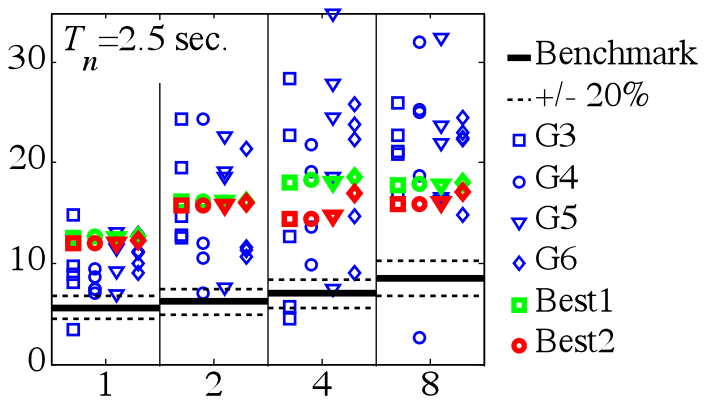

(b) Bilinear systems
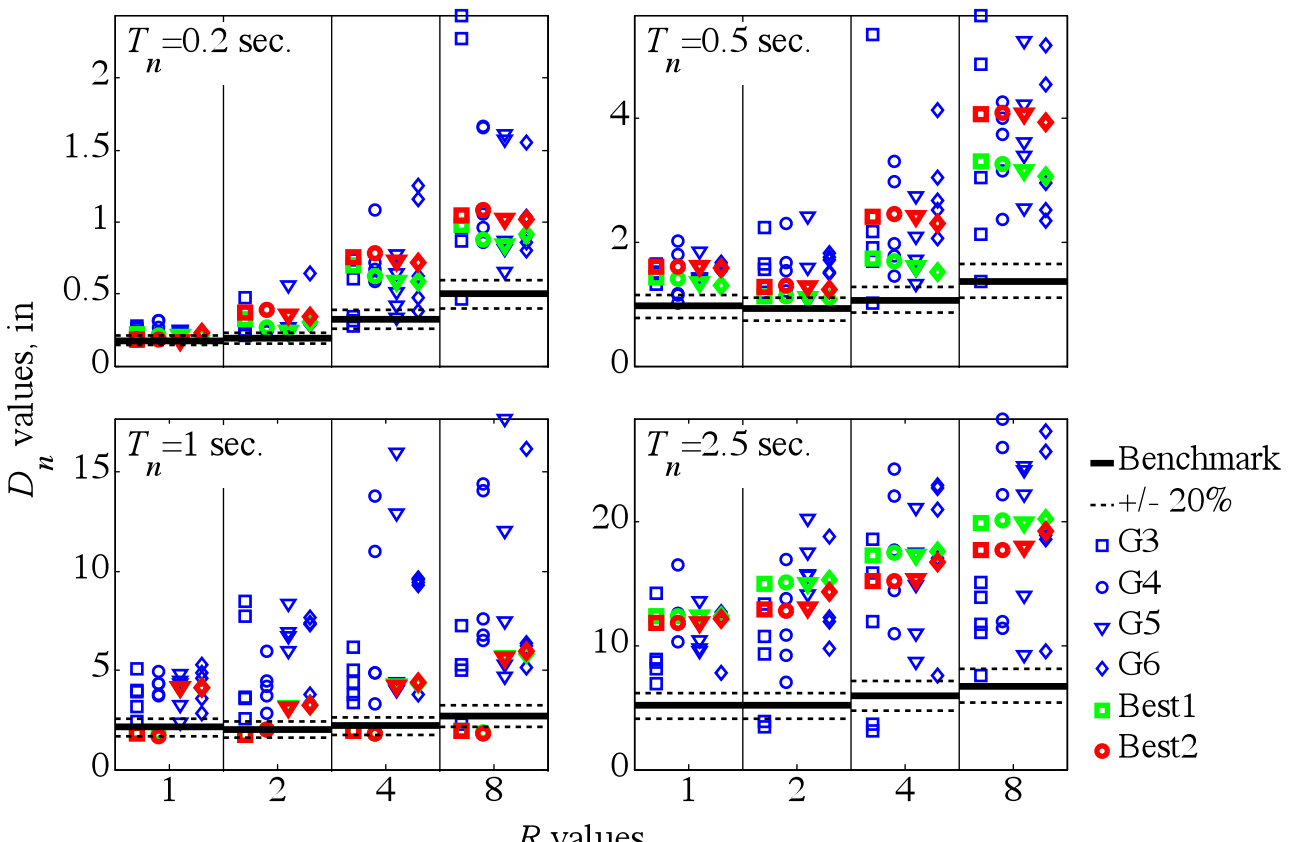

\section{0}

10

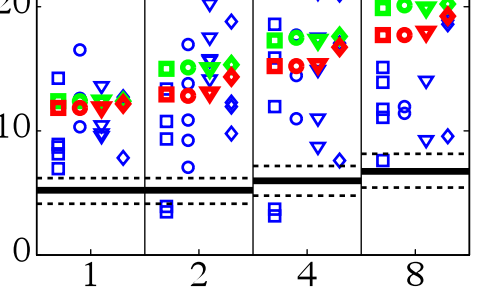

口 G3

$\circ \mathrm{G} 4$

$\nabla \mathrm{G} 5$

$\diamond \mathrm{G6}$

Best1

- Best2

Figure 8. Comparison of benchmark and ASCE/SEI 7 deformation values for (a) elastic-perfectly-plastic, and (b) bilinear systems. The benchmark engineering demand parameters (EDPs) correspond to the mean of 30 deformation values. The deformation values for each set scaled by the ASCE/SEI 7 procedure are obtained as the maximum deformation values of 3, 4,5 and 6 records in each of seven sets. Included also are sets Best1 and Best2. 
(a) Elastic-perfectly-plastic systems

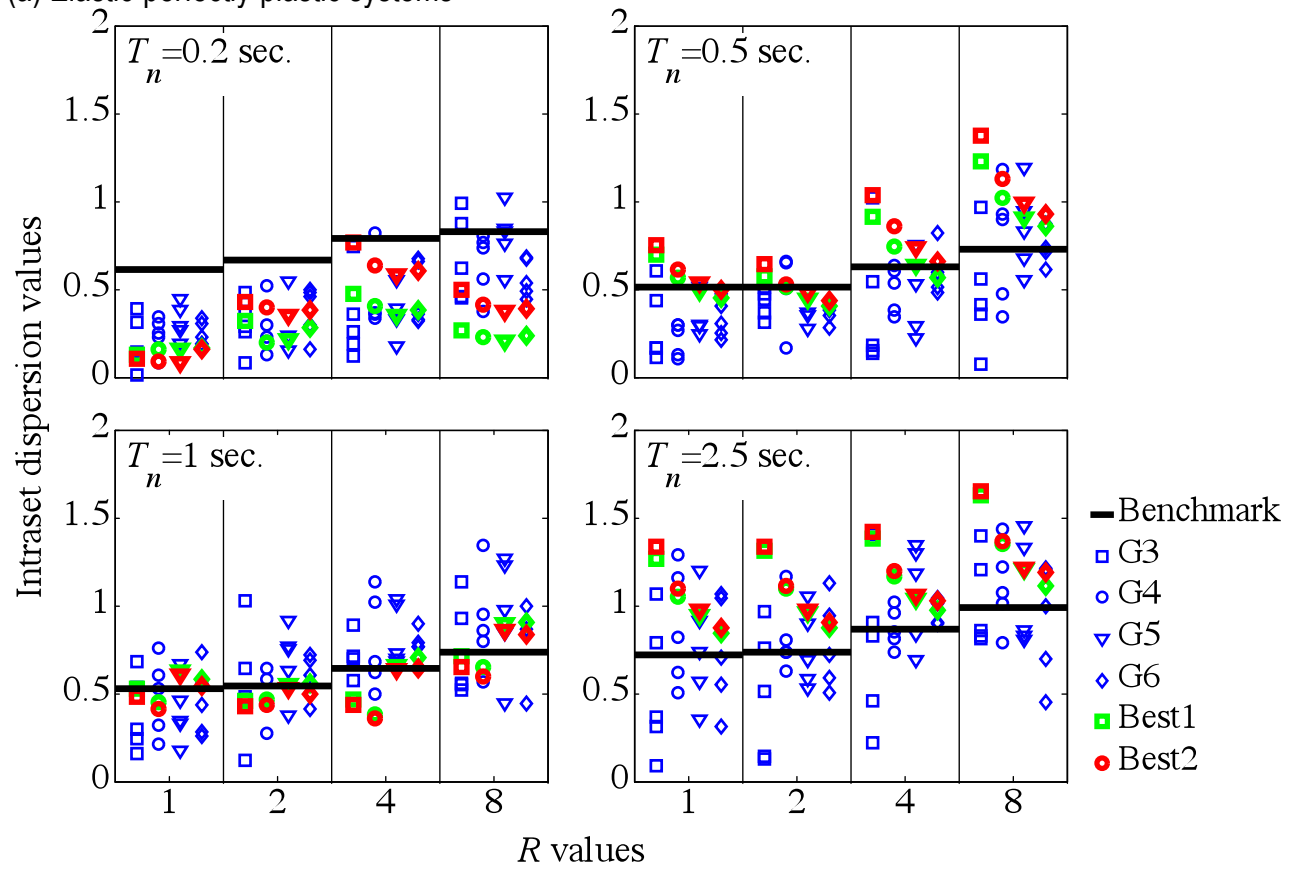

(b) Bilinear systems
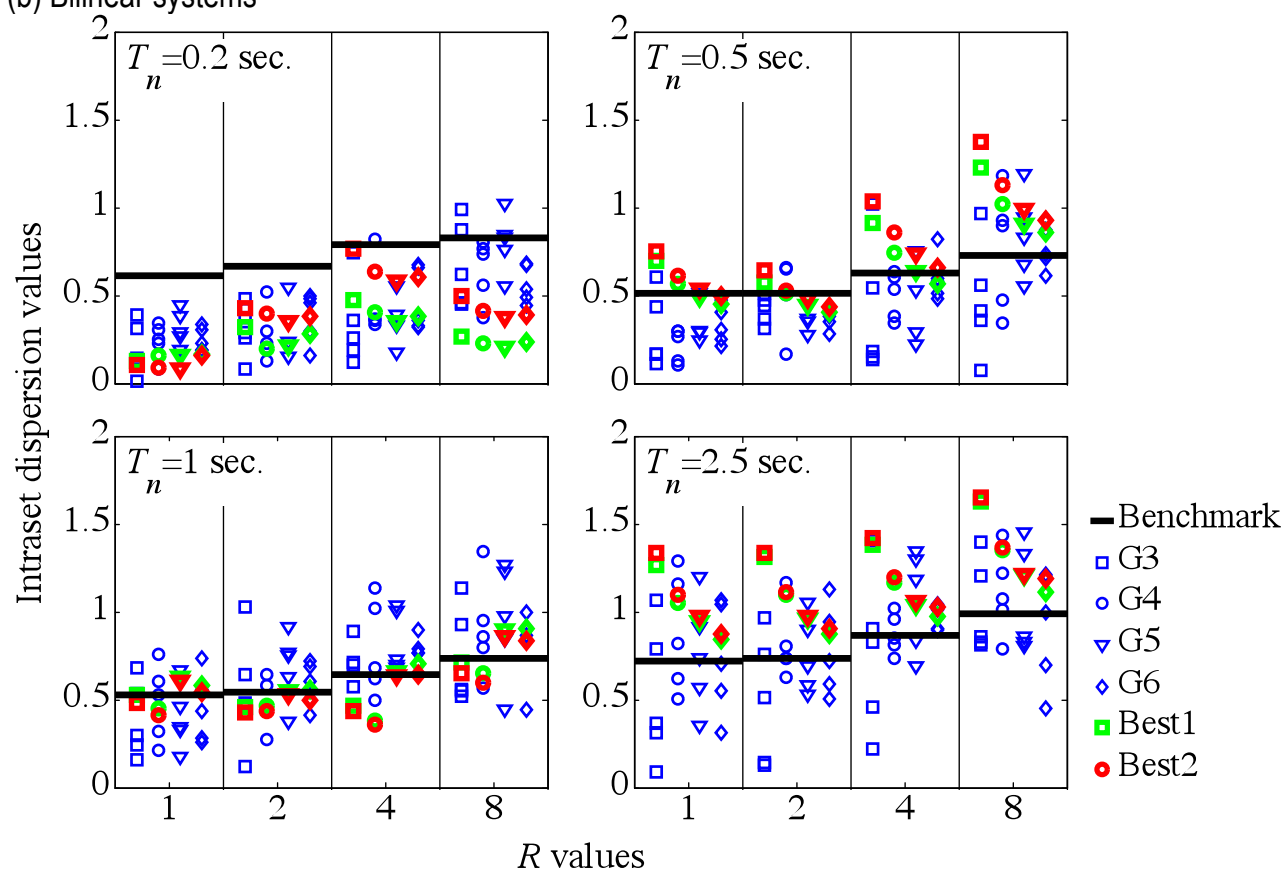

Figure 9. Comparison of benchmark and ASCE/SEI 7 intra-set (that is, within set) dispersion values for (a) elasticperfectly-plastic, and (b) bilinear systems. G3, G4, G5, and G6 contain seven sets of 3, 4, 5 and 6 ground-motion records, respectively. Lognormal distribution is assumed. 
(a) Elastic-perfectly-plastic systems

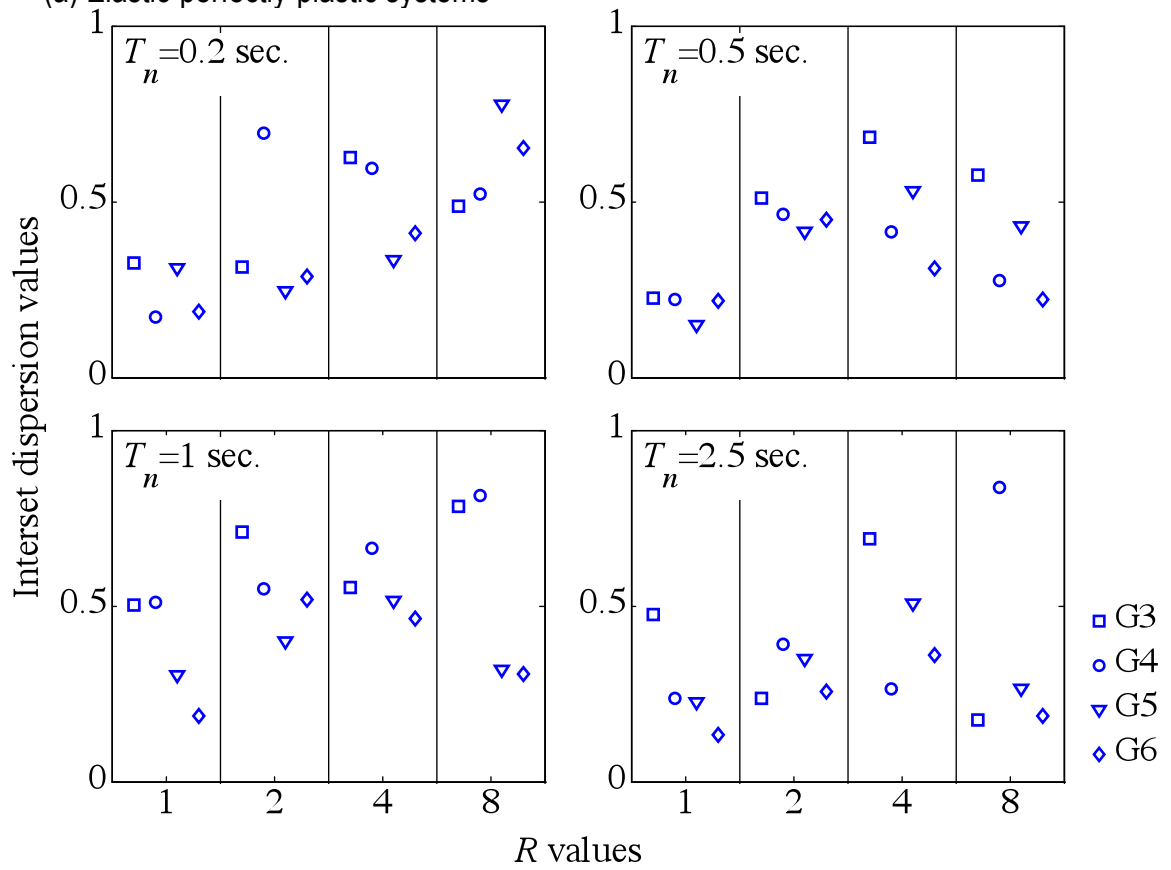

(b) Bilinear systems

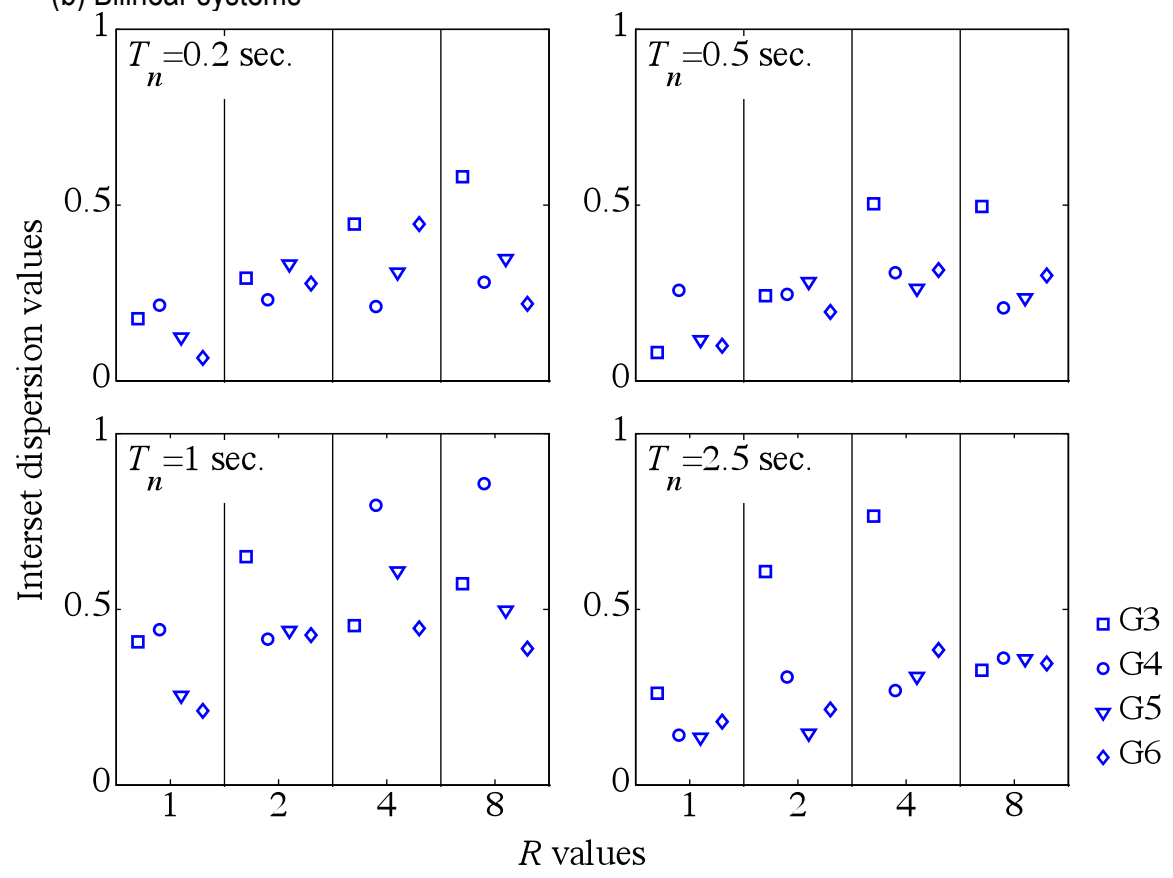

Figure 10. ASCE/SEI 7 inter-set (that is, set-to-set) dispersion values for (a) elastic-perfectly-plastic, and (b) bilinear systems. G3, G4, G5, and G6 contain seven sets of 3, 4, 5 and 6 ground-motion records, respectively. Lognormal distribution is assumed. 

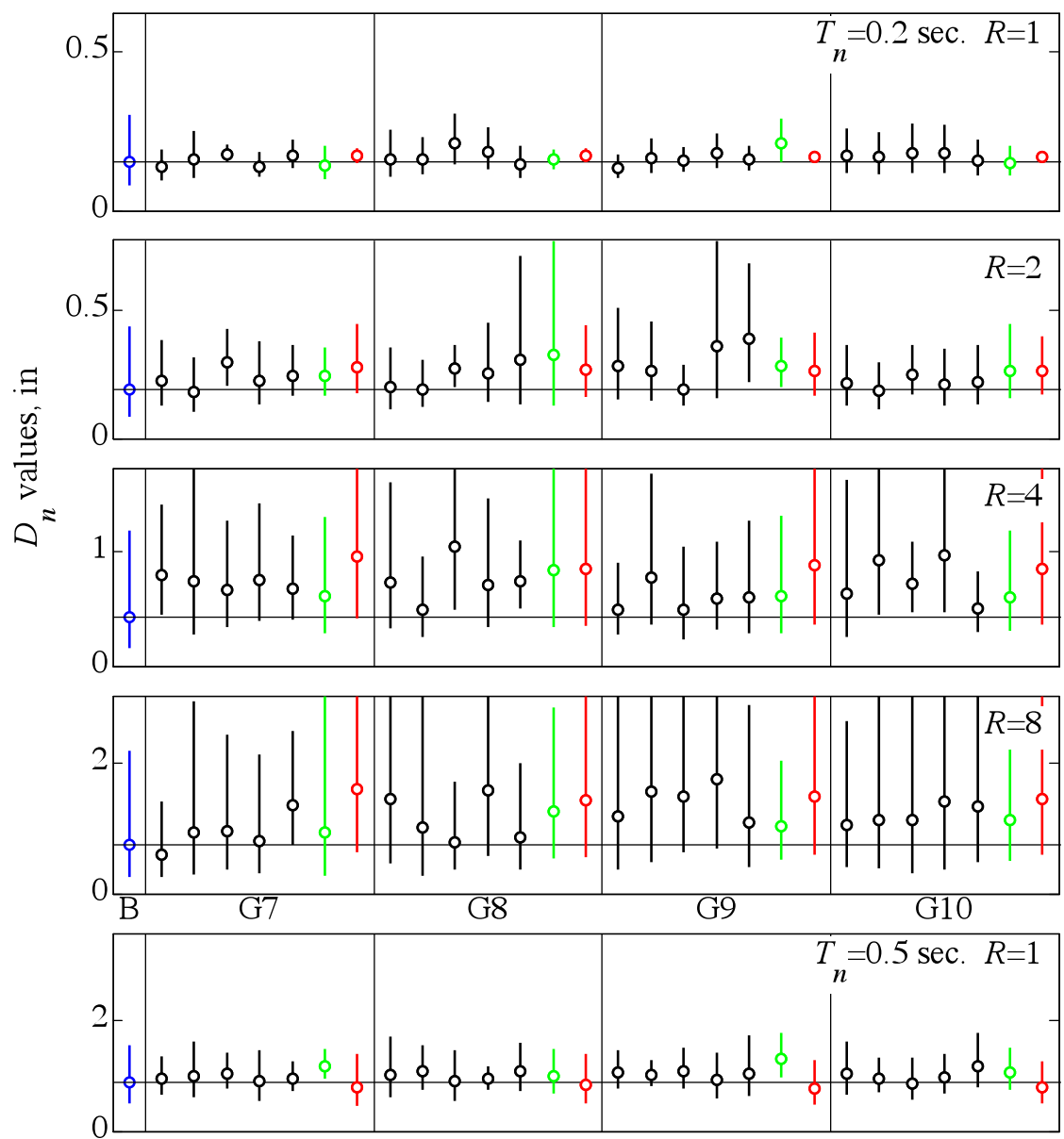

- Benchmark

- Set $i$

-Best1

$\rightarrow$ Best2
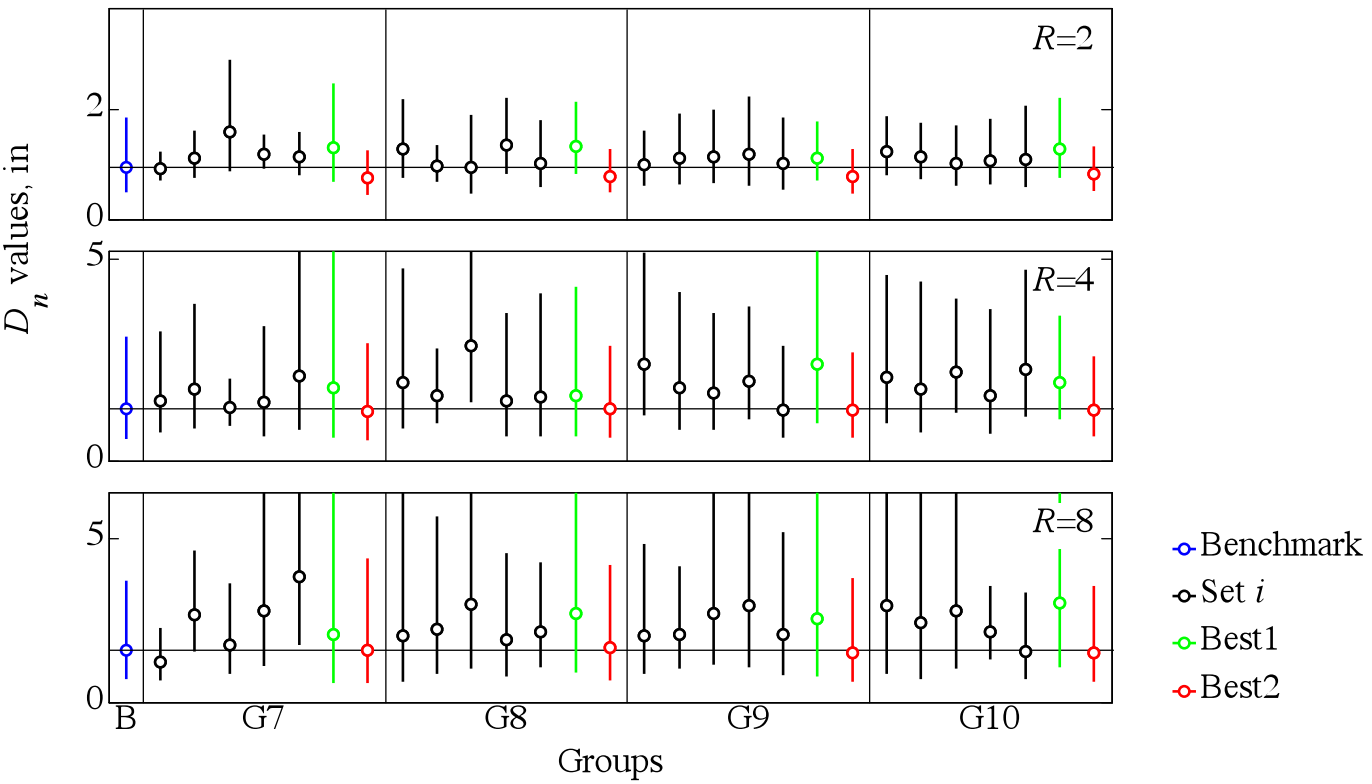

Figure 11. Range of inelastic deformation values for elastic-perfectly-plastic systems with $T_{n}=0.2$ (top four panels) and $0.5 \mathrm{sec}$ (bottom four panels), and $\mathrm{R}=1,2,4$, and 8 for sets of 7, 8, 9, and 10 ground-motion records denoted respectively as $\mathrm{G} 7, \mathrm{G} 8, \mathrm{G} 9$, and $\mathrm{G} 10$. The blue dot and the vertical line represent the benchmark (B) median deformation value $\pm \sigma$ assuming a lognormal distribution. For each set, the vertical line and the dot represent the range of the data set and median deformation value, respectively. 

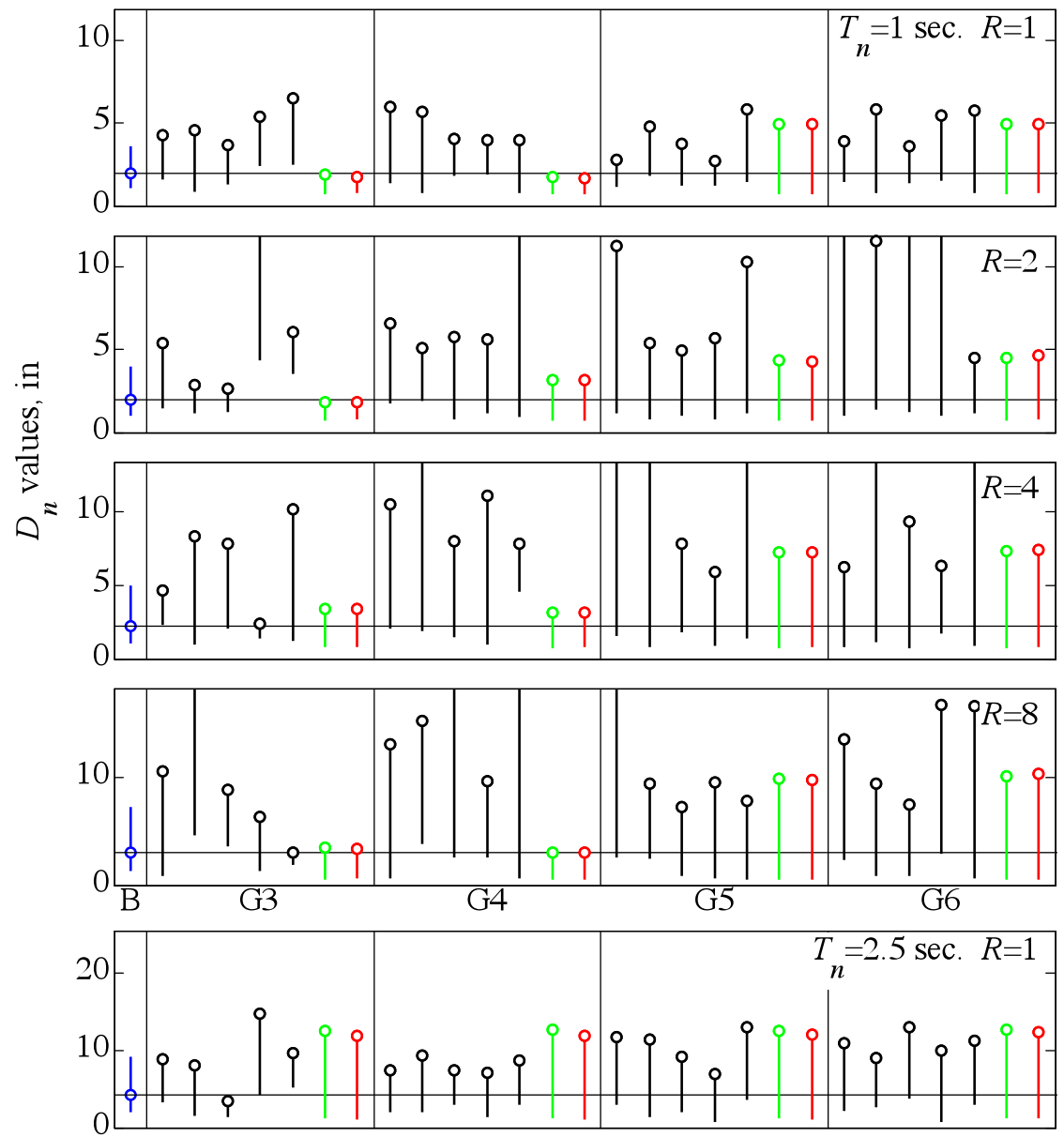

- Benchmark

- Set $i$

$\ldots$ Best1

$\rightarrow$ Best2
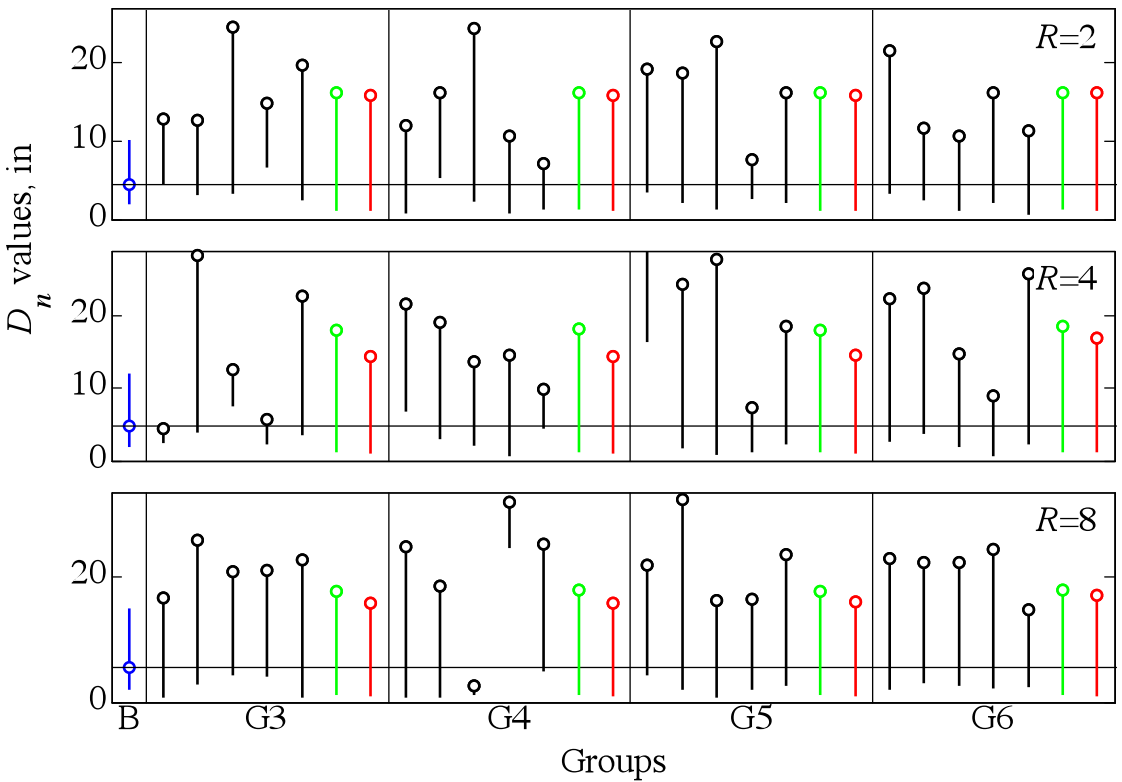

- Benchmark

- Set $i$

-Best1

-Best2

Figure 12. Range of inelastic deformation values for elastic-perfectly-plastic systems with $T_{n}=1$ (top four panels) and $2.5 \mathrm{sec}$ (bottom four panels), and $\mathrm{R}=1,2,4$, and 8 for sets of 7, 8, 9, and 10 ground-motion records denoted respectively as $\mathrm{G} 7, \mathrm{G} 8, \mathrm{G} 9$, and $\mathrm{G} 10$. The blue dot and the vertical line represent the benchmark (B) median deformation value $\pm \sigma$ assuming a lognormal distribution. For each set, the vertical line and the dot represent the range of the data set and median deformation value, respectively. 

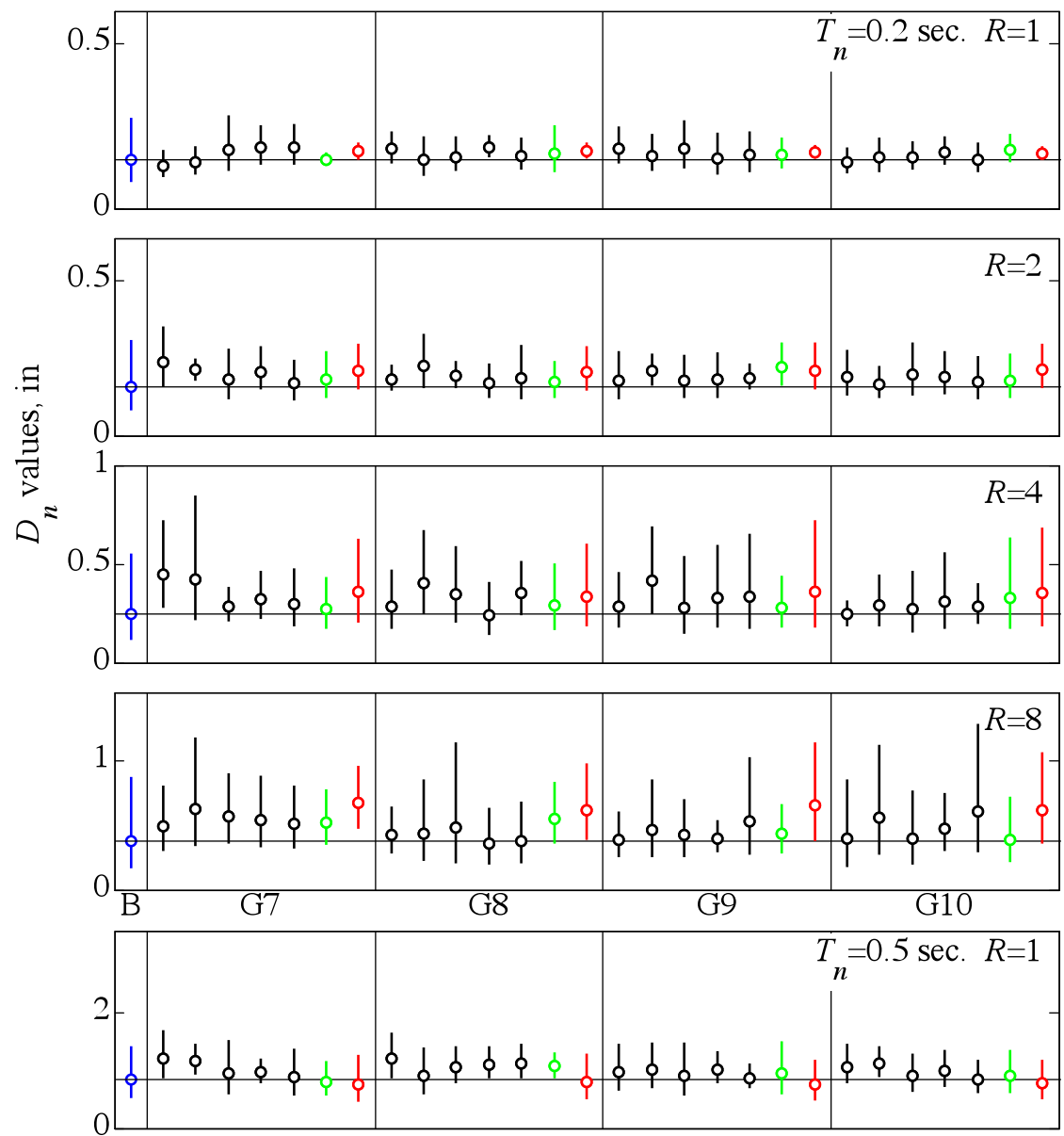

- Benchmark

- Set $i$

- - Best1

-Best2
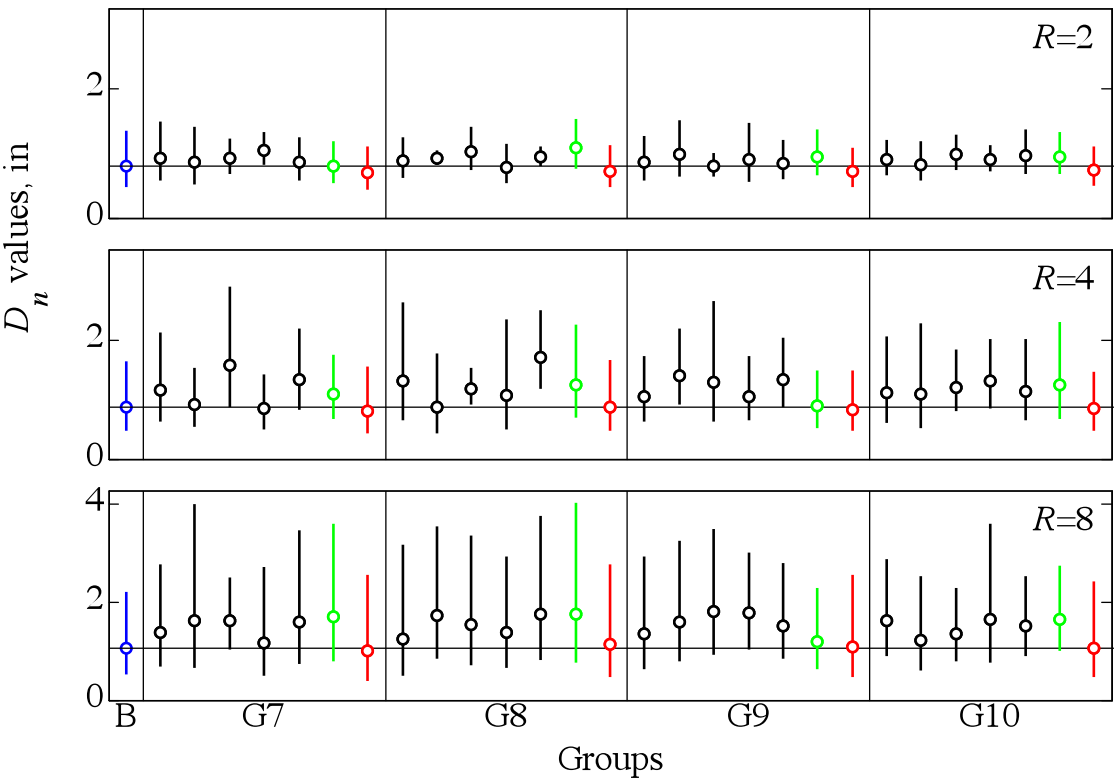

-Benchmark

- Set $i$

-Best1

$\circ$ Best2

Figure 13. Range of inelastic deformation values for bilinear systems with $T_{n}=0.2$ (top four panels) and $0.5 \mathrm{~s}$ (bottom four panels), and $\mathrm{R}=1,2,4$, and 8 for sets of 7, 8, 9, and 10 ground-motion records denoted respectively as $\mathrm{G} 7, \mathrm{G} 8, \mathrm{G} 9$, and $\mathrm{G} 10$. The blue dot and the vertical line represent the benchmark (B) median deformation value $\pm \sigma$ assuming a lognormal distribution. For each set, the vertical line and the dot represent the range of the data set and median deformation value, respectively. 

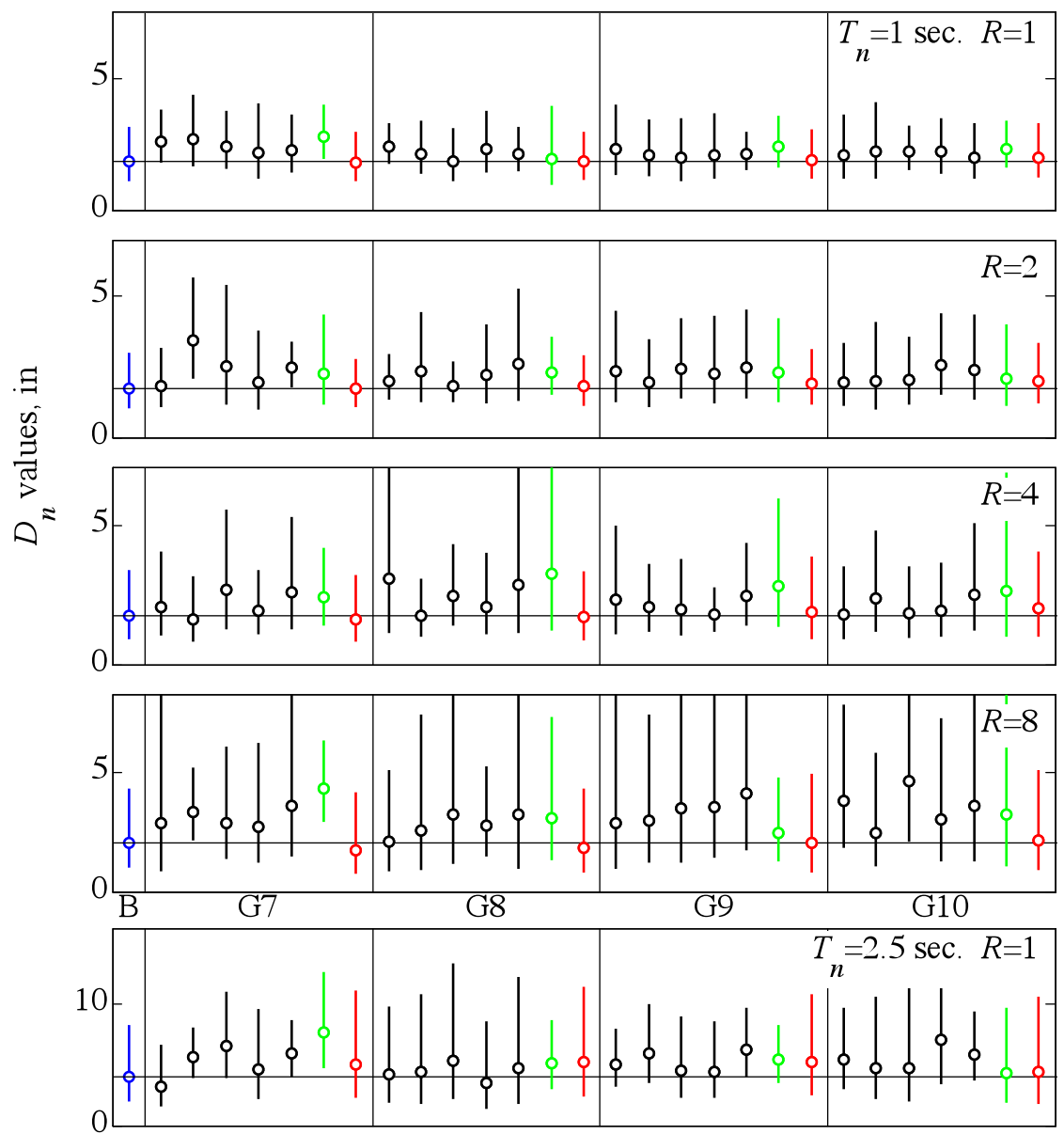

- Benchmark

- Set $i$

-Best1

-Best2
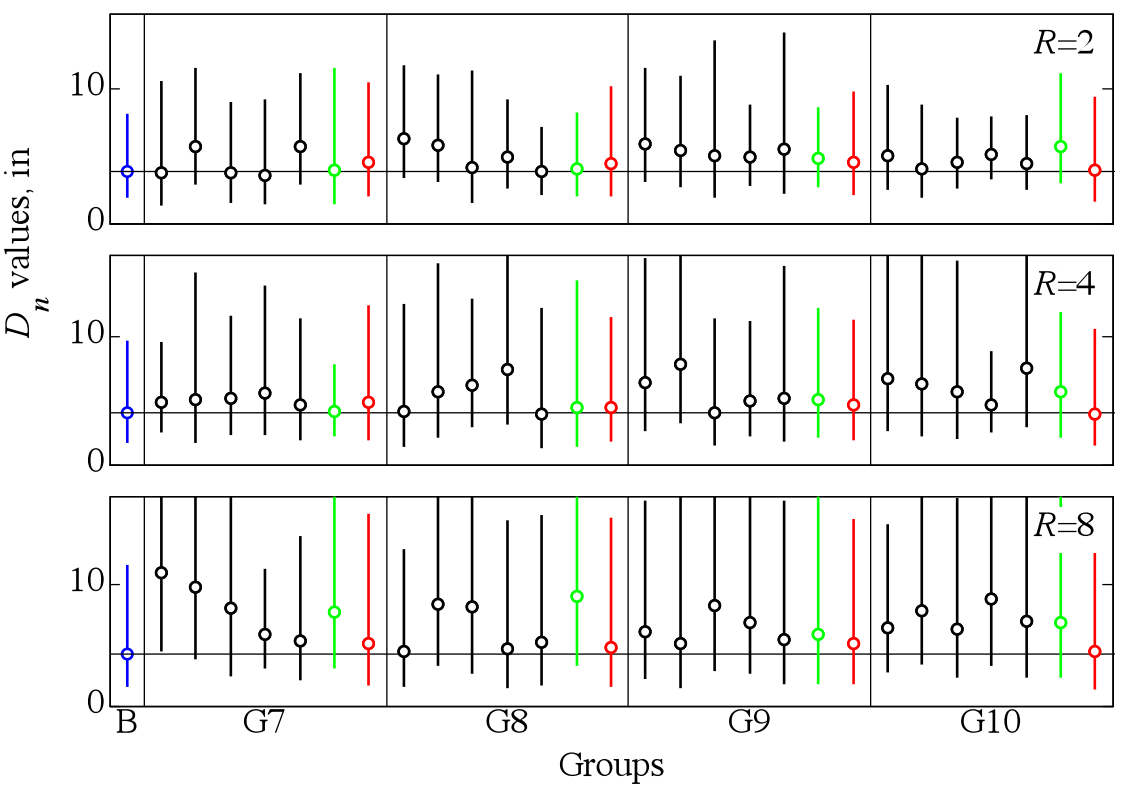

- Benchmark

- Set $i$

-Best1

$\circ$ Best2

Figure 14. Range of inelastic deformation values for bilinear systems with $T_{n}=1$ (top four panels) and $2.5 \mathrm{sec}$ (bottom four panels), and $\mathrm{R}=1,2,4$, and 8 for sets of 7, 8, 9, and 10 ground-motion records denoted respectively as G7, G8, G9, and G10. The blue dot and the vertical line represent the benchmark (B) median deformation value $\pm \sigma$ assuming a lognormal distribution. For each set, the vertical line and the dot represent the range of the data set and median deformation value, respectively. 
(a) Elastic-perfectly-plastic systems

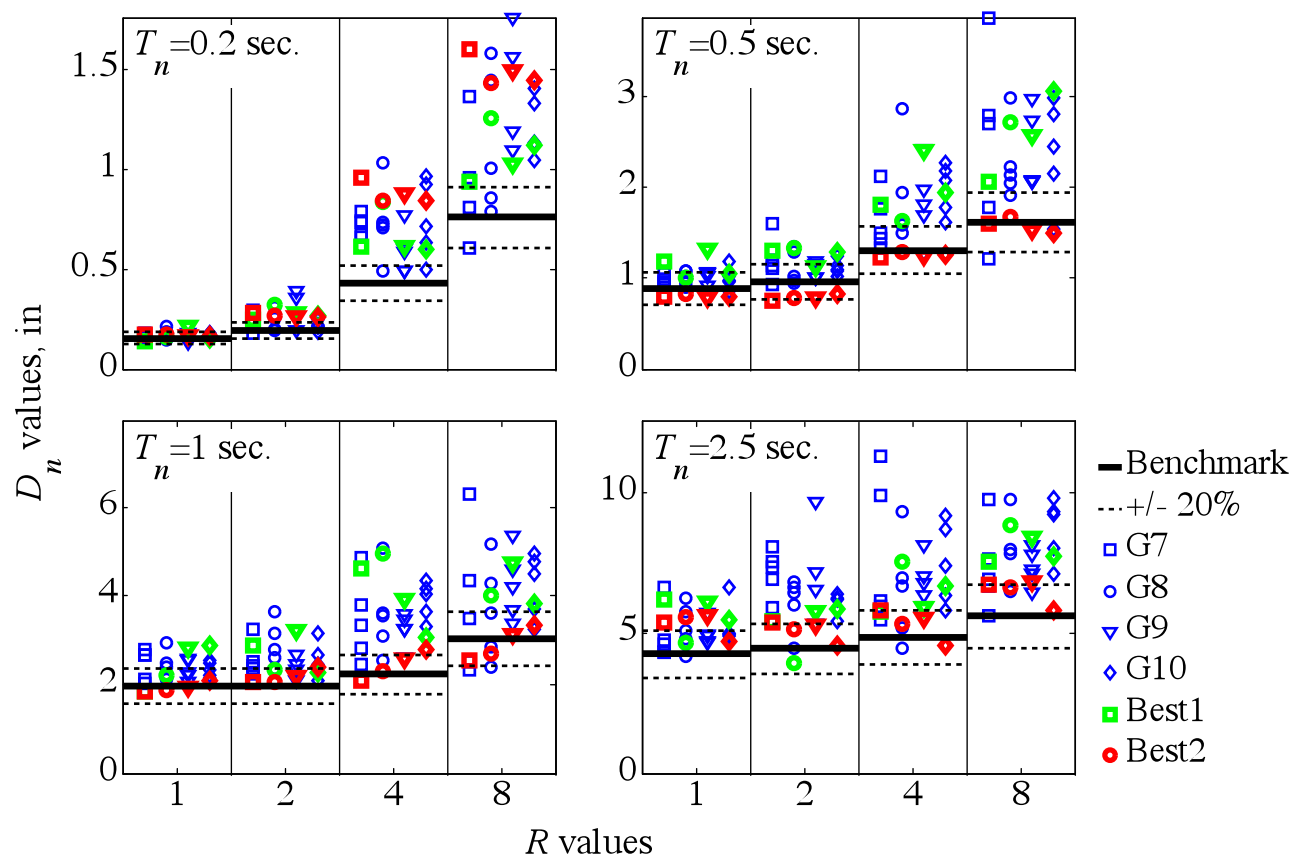

(b) Bilinear systems

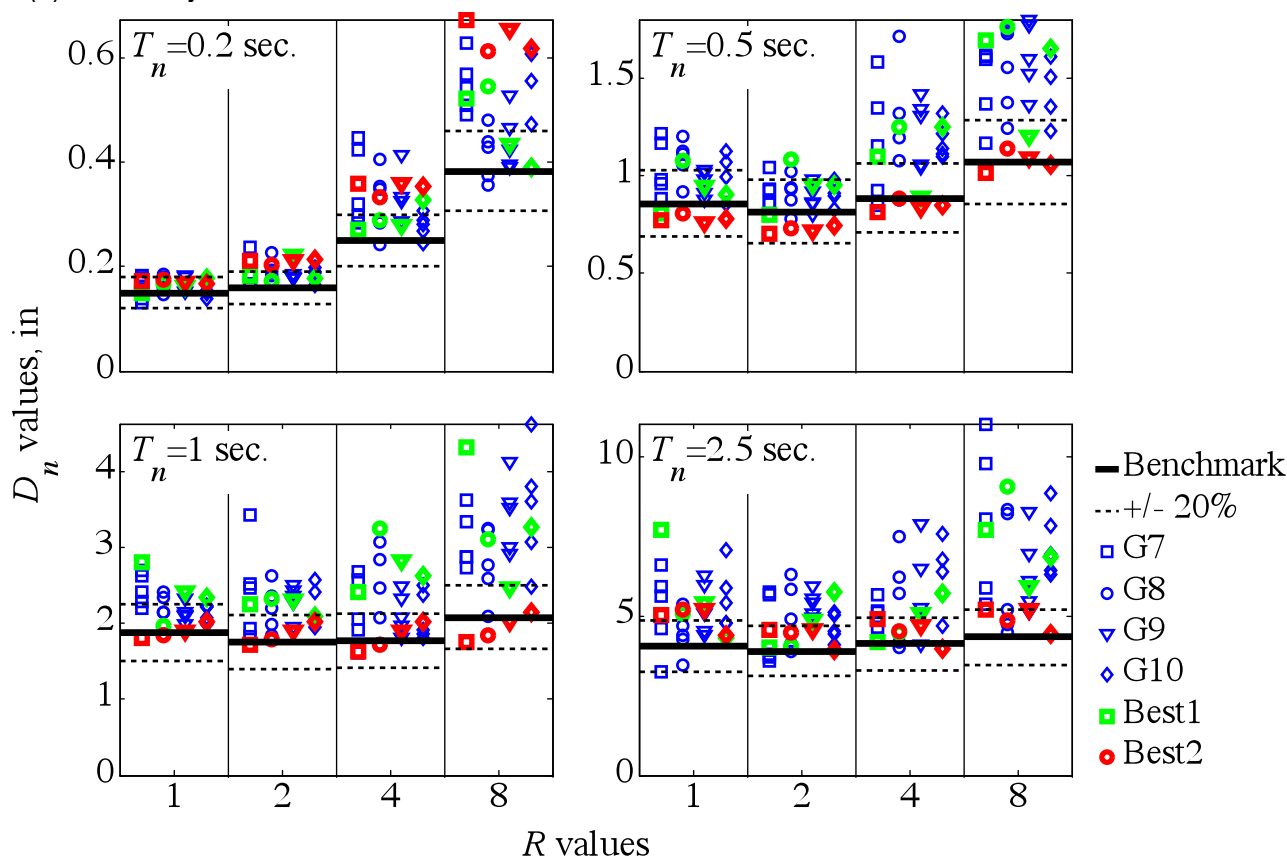

Figure 15. Benchmark and ASCE/SEI 7 deformation values for (a) elastic-perfectly-plastic, and (b) bilinear systems. The benchmark EDPs correspond to the median of 30 deformation values. The deformation values for each set scaled by the ASCE/SEI 7 procedure are obtained as the median of 7, 8, 9, and 10 deformation values. Included also are sets Best1 and Best2. 
(a) Elastic-perfectly-plastic systems

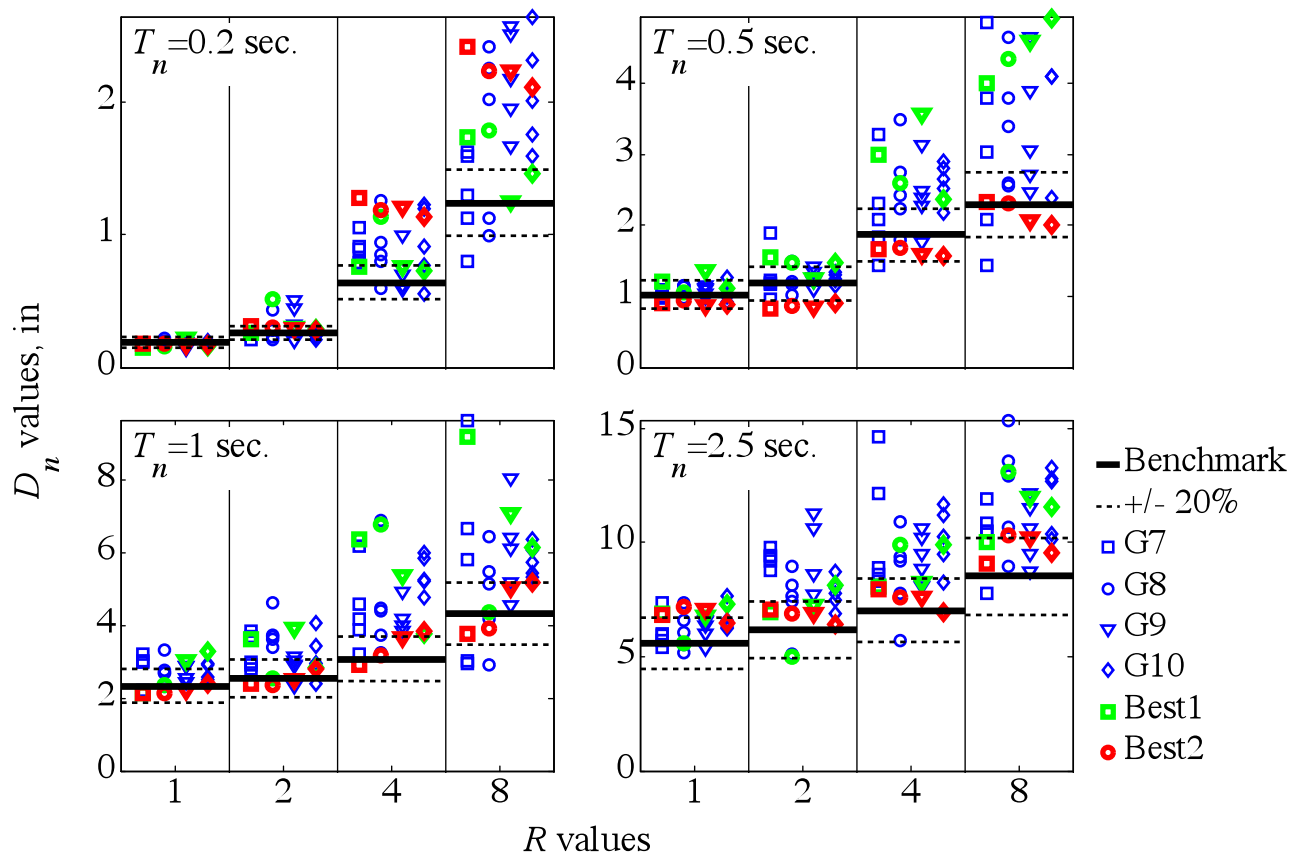

(b) Bilinear systems

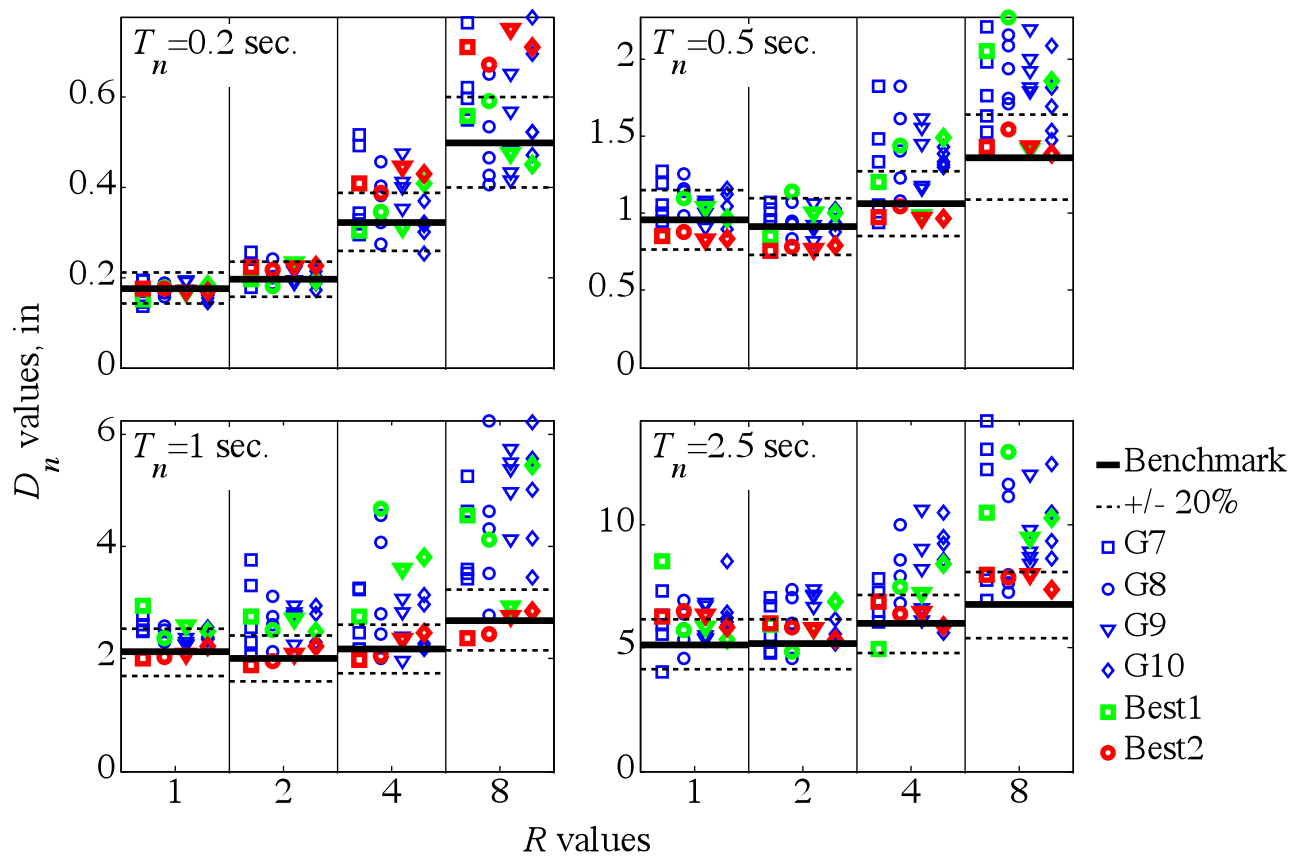

Figure 16. Benchmark and ASCE/SEI 7 deformation values for (a) elastic-perfectly-plastic, and (b) bilinear systems. The benchmark EDPs correspond to the mean of 30 deformation values. The deformation values for each set scaled by the ASCE/SEI 7 procedure are obtained as the mean of 7, 8, 9, and 10 deformation values. Included also are sets Best1 and Best2. 
(a) Elastic-perfectly-plastic systems

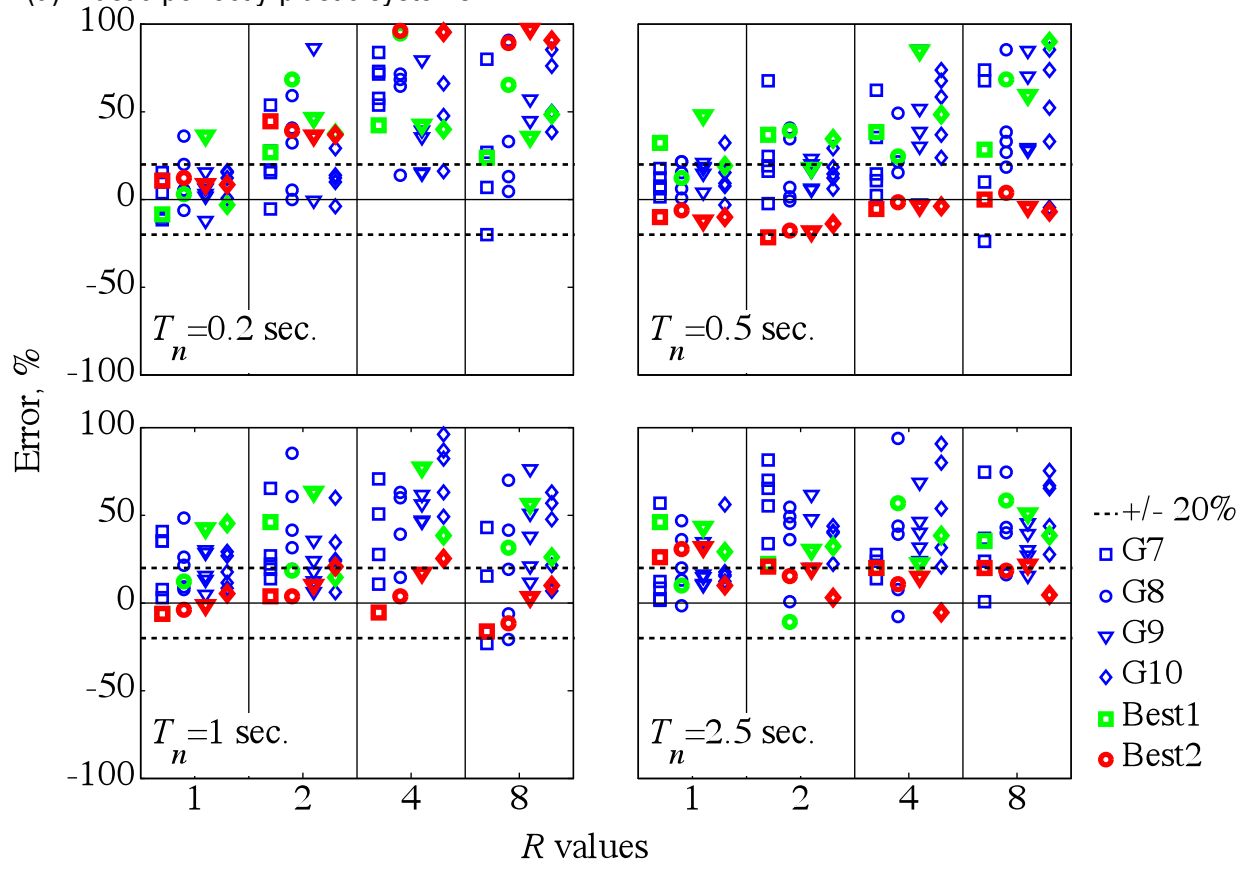

(b) Bilinear systems
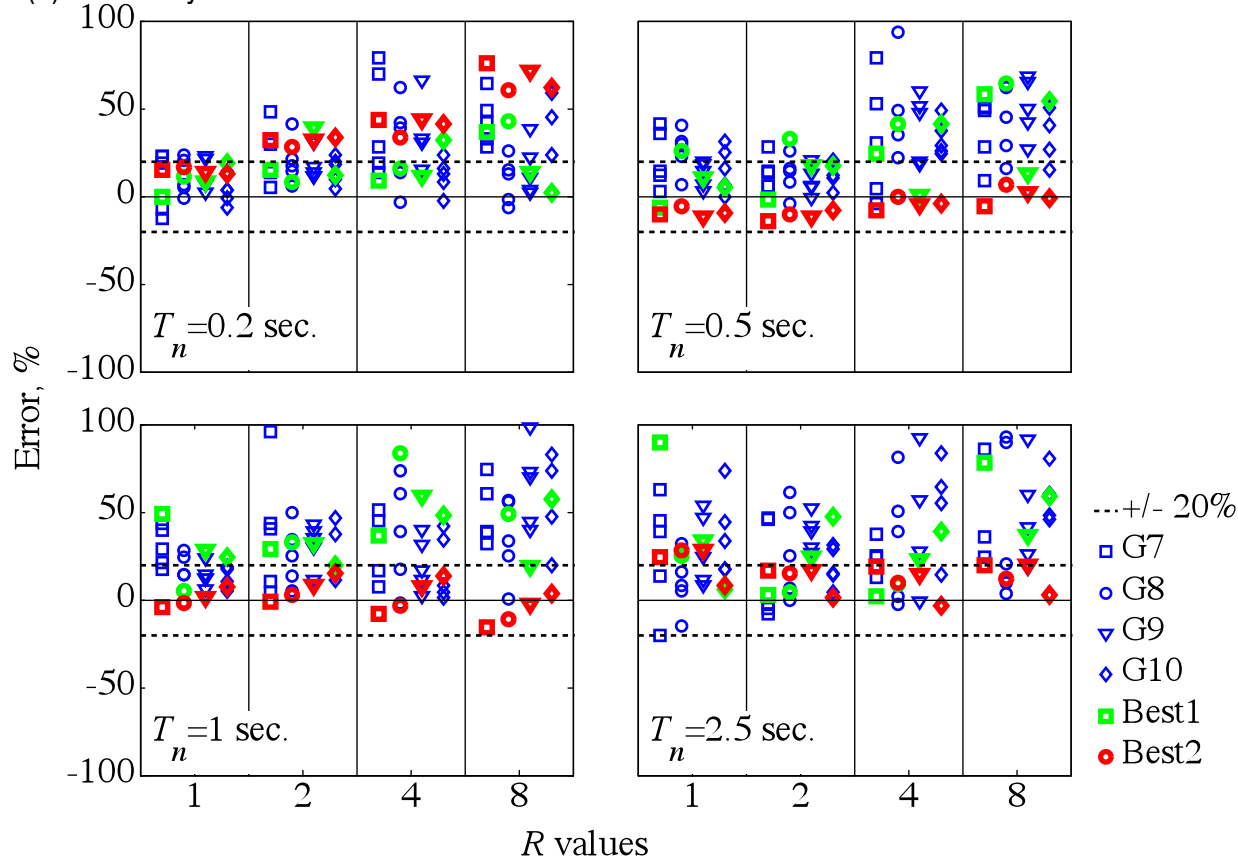

Figure 17. Error in the estimation of median deformation values for (a) elastic-perfectly-plastic and (b) bilinear systems. The benchmark EDPs correspond to the median of 30 deformation values. The deformation values for each set scaled by the ASCE/SEI 7 procedure are obtained as the median of 7, 8, 9, and 10 deformation values. Included also are sets Best1 and Best2. 
(a) Elastic-perfectly-plastic systems

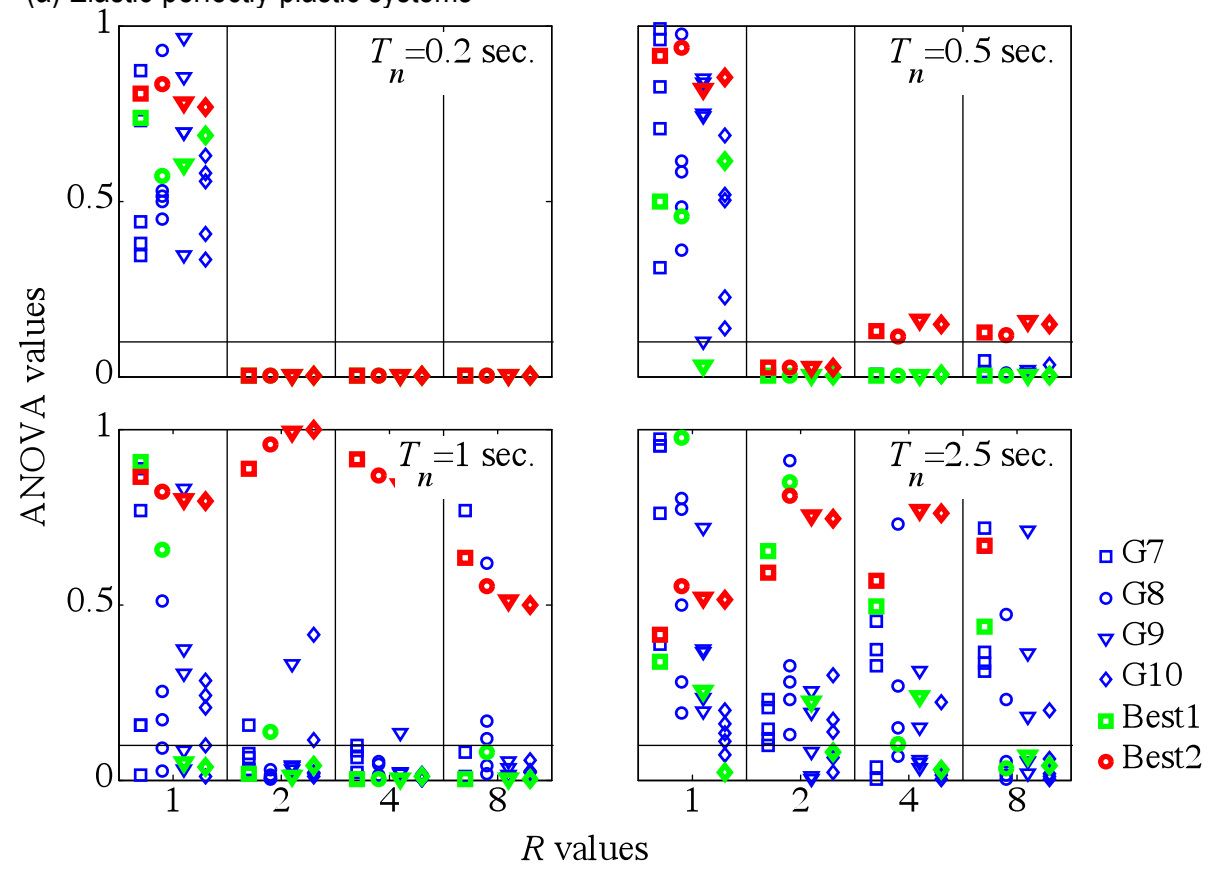

(b) Bilinear systems

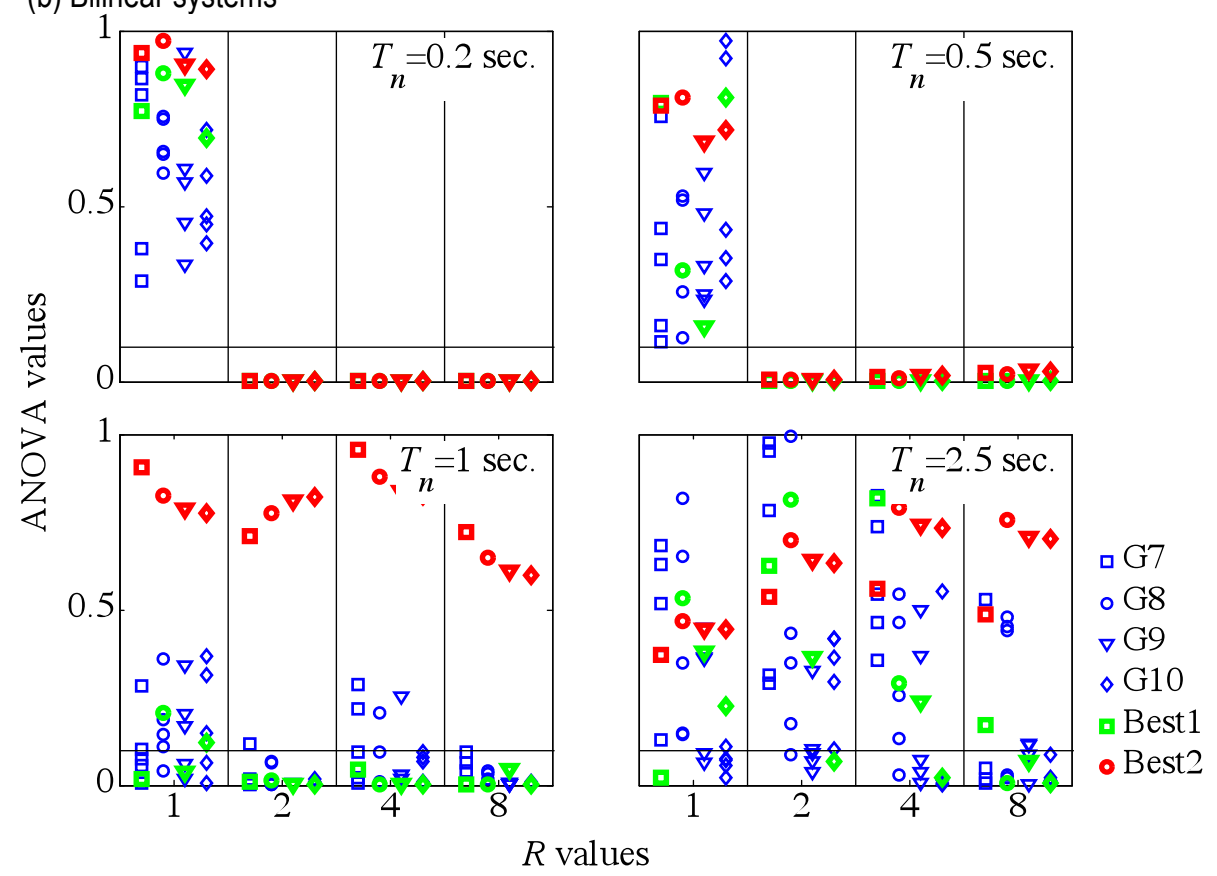

Figure 18. ANOVA values for (a) elastic-perfectly-plastic, and (b) bilinear systems. The ANOVA test compares deformation values from each set against the benchmark deformation values. 
(a) Elastic-perfectly-plastic systems

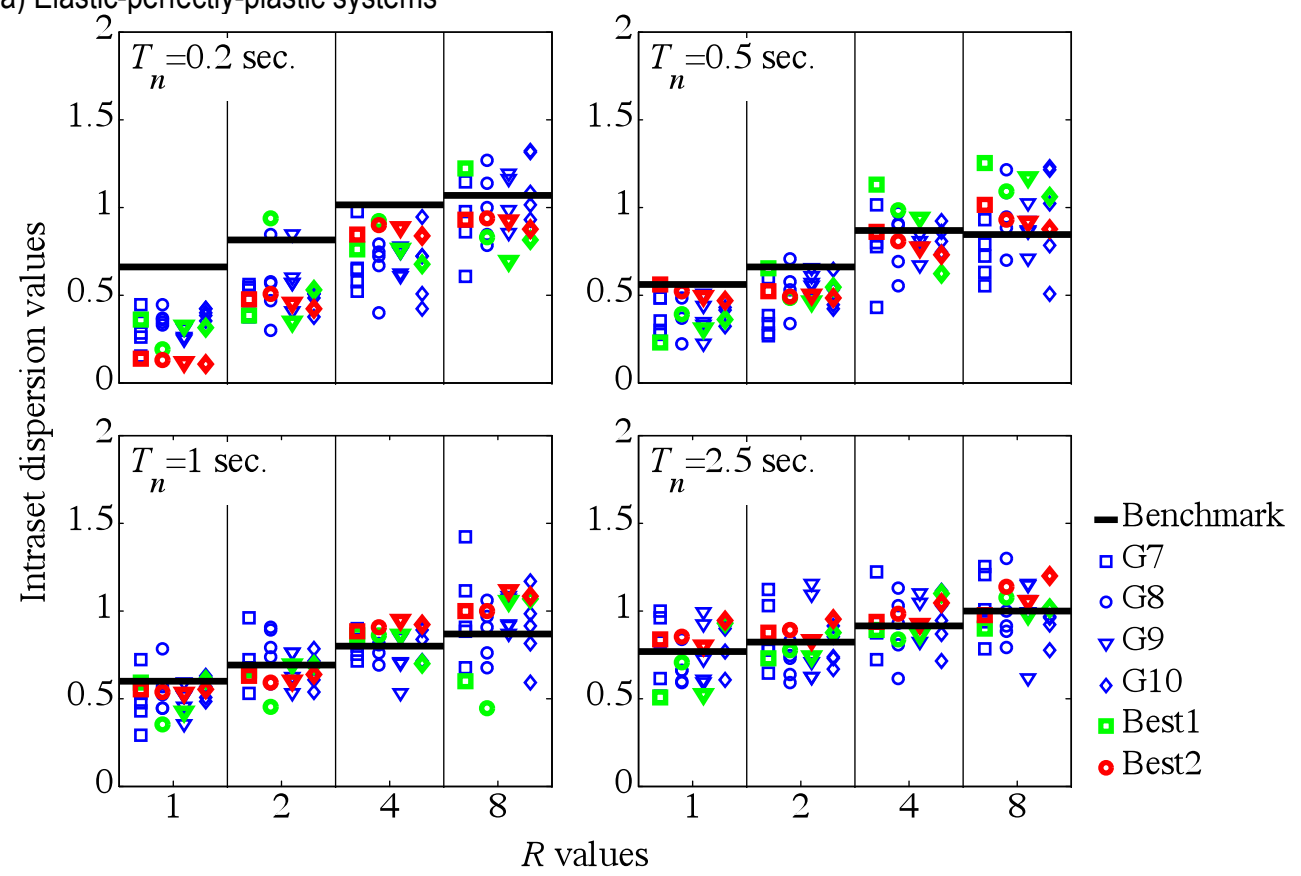

(b) Bilinear systems
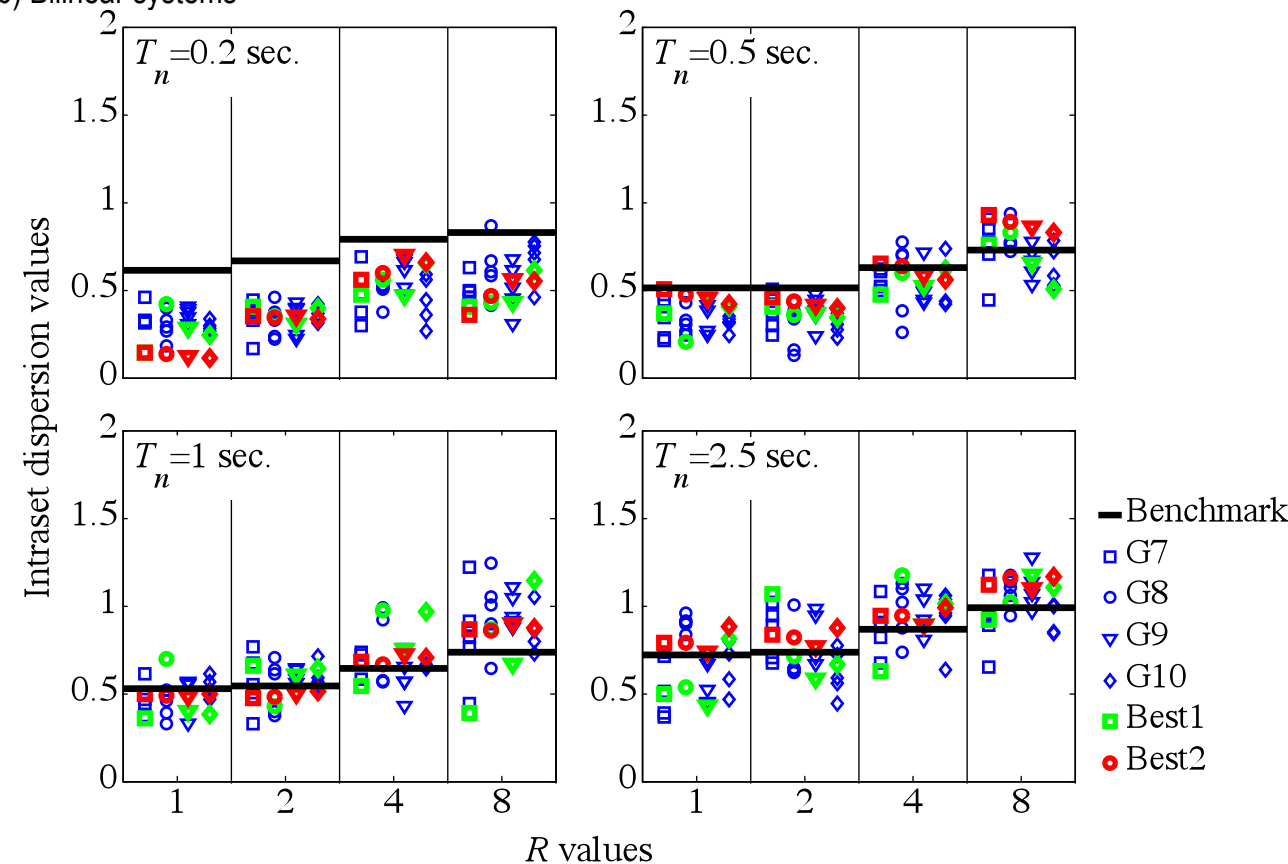

Figure 19. Benchmark and ASCE/SEI 7 intra-set dispersion values for (a) elastic-perfectly-plastic, and (b) bilinear systems. Lognormal distribution is assumed. 
(a) Elastic-perfectly-plastic systems

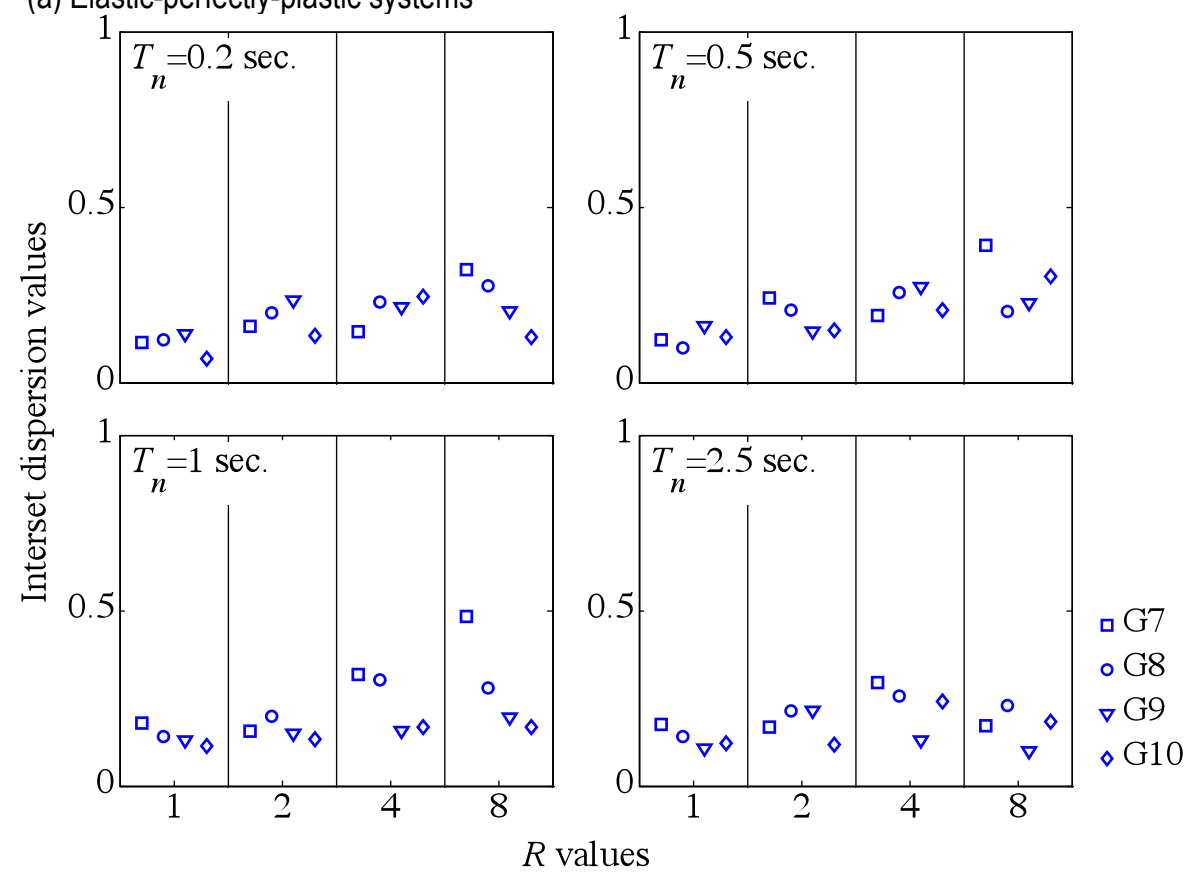

(b) Bilinear systems

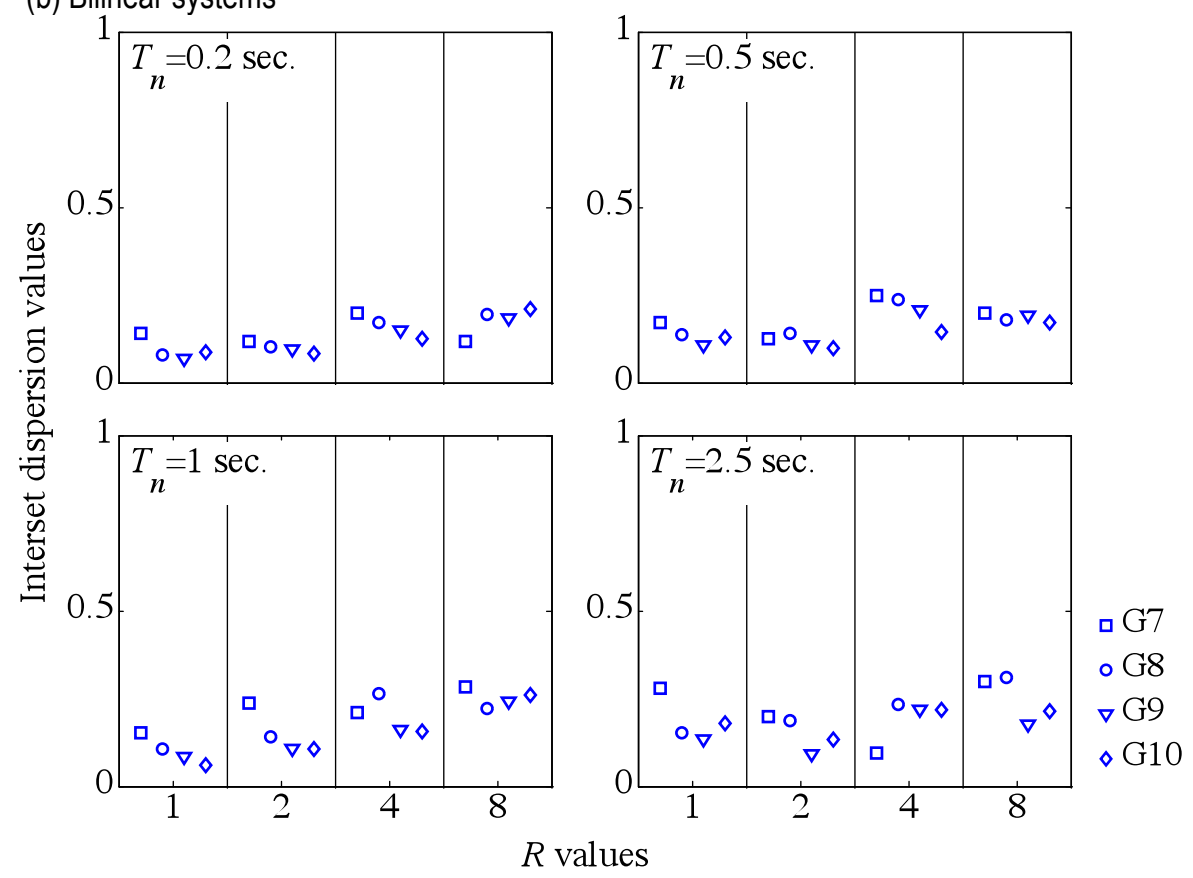

Figure 20. ASCE/SEI 7 inter-set dispersion values for (a) elastic-perfectly-plastic, and (b) bilinear systems. Lognormal distribution is assumed. 